\title{
DE LAS TRES ÍNSULAS A JAFARÍN. LAS ISLAS CHAFARINAS Y SU ENTORNO EN LA ANTIGÜEDAD Y MEDIEVO
}

\author{
MANUEL ARAGÓN GÓMEZ \\ Profesor-tutor UNED \\ Instituto de Cultura Mediterránea
}

El devenir histórico del archipiélago de las islas Chafarinas está ligado a la presencia española en la costa africana, aunque su escasa distancia de la costa la vincula estrechamente a los avatares de la vasta región de Quebdana, entre el cabo de Tres Forcas y el río Muluya.

Las características geoestratégicas que presentan las islas, a medio camino entre las viejas ciudades deRusaddir (Melilla) y Siga (Takembrit), antigua capital del reino Massaesyli, y su cercanía a dos grandes hitos geográficos a lo largo de toda la historia del mar de Alborán como son el Cabo Ras el Ma y el río Muluja, propició que quedaran reflejadas en cuantas descripciones tuviese como protagonista la costa norteafricana, no solamente en época antigua sino también en el medievo.

Una costa, la del sur del mar de Alborán, en la que pusieron sus ojos cada uno de los pueblos que habitaron el Mediterráneo occidental, siendo señalados desde el periplo de Scylax en la antigüedad (IV a.C .) o durante la hegemonía romana en el "Itinerario de Antonino" (III d.C.), a los distintos autor es árabes como El Bekri (XI d.C.) o el ceutí Idrisi (XII d.C.), en época islámica.

Afirmar que las próximas líneas puedan arrojar luz a la historia antigua o medieval de las islas sería pretencioso, puesto que la falta de datos tan solo permiten esbozar puntualmente la trayectoria de estas islas con unas pequeñas pinceladas de su contexto. Las innumerables lagunas deberán ser completadas en las próximas décadas por las investigaciones que lleven a cabo los diferentes equipos hispano-marroquíes desde las dos orillas.

Junto a las siempre insuficientes fuentes históricas, las investigaciones arqueológicas se trazan como impr escindibles para el conocimiento histór ico de este archipiélago y su entor no, que lejos de estancar se crece por años. Y no lo hace exclusivamente de periodos prehistóricos sino también de momentos clásicos, hecho atestiguado por los recientes hallazgos de restos de ánforas de tipo 
itálico, de ahí la importancia de retomar los proyectos arqueológicos en las islas, suspendidos hace apenas unos años.

\section{EL PRIMER MILENIO ANTES DE NUESTRA ERA}

El archipiélago de las islas Chaf arinas no debió pasar inad vertido en los inicios de la na vegación en la cuenca Mediter ránea por lo que la colonización fenicia de occidente no sería ajena al conocimiento de estas tres islas y, con toda probabilidad, fijaría un establecimiento en fechas tempranas.

La ciudad de Tiro, al sur del Líbano, capitalizaría este proceso colonial estimulado por múltiples factores, siendo la falta de materias primas, la presión tributaria asiria o el déficit agrícola las que impulsarían una red de factorías por todo el Mediterráneo extendiéndose hasta la costa atlántica marroquí y portuguesa.

Los fenicios, utilizando rutas de navegación tradicionales, potenciaron una red de enclaves para facilitar el intercambio de productos. La primera fundación en el norte de África se realizó en las postrimerías del siglo X a.C. en el golfo de Túnez, en la conocida Útica mucho antes de la existencia de la mítica Cartago, extendiéndose posteriormente a la costa del Mediteráneo occidental y alAtlántico en el sigloVIII a.C., entre las que destacarían las ciudades deGadir (Cadiz) y Lixus (Larache).

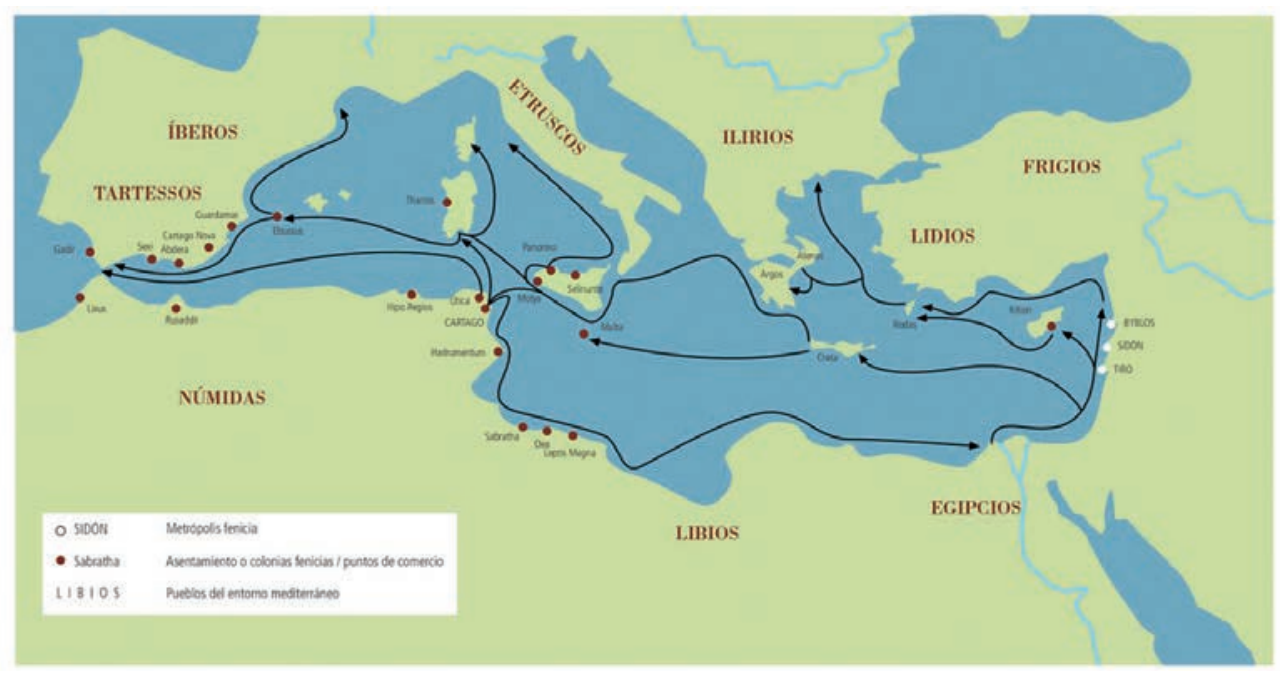

La colonización fenicia 
Restos arqueológicos en puntos coster os al sur de Alborán como Sidi Dris (Boudinar, Nador), Ras Quebdana (Nador), Casa del Gobernador (Melilla) o Berkane (Bohout, Uxda) per miten suponer una amplia v ariedad de tipologías de los establecimientos desde los primeros momentos de la colonización. Una característica frecuente de estos centros es la similitud en el patrón de asentamientos ubicados en promontorios o islotes que hacían más viables su defensa y per mitirían posteriormente el impulso a tier ra firme. Otra característica sería la cercanía a un cur so fluvial y el Muluya en este sentido, uno de los ríos más largos de Marruecos con más de medio millar de kilómetros, despertaría gran interés por su navegabilidad y alta posibilidad para realizar intercambios con las pob laciones autóctonas localizadas en su r ibera. El curso del Muluya o Mulucha, que mencionarán la mayoría de las fuentes clásicas como Scylax (111), Estrabon (XVII, 3, 6), Salustio (XXIX, 7), Plinio (V, 19), Mela (I, 5, 25-30) el Malva de Ptolomeo (Ptol IV, I, 3), definirá la frontera histórica entre la antigua Mauritania (Marruecos) y Numidia (Argelia) así como posteriormente la Mauretania Tingitana de la Cesariense.

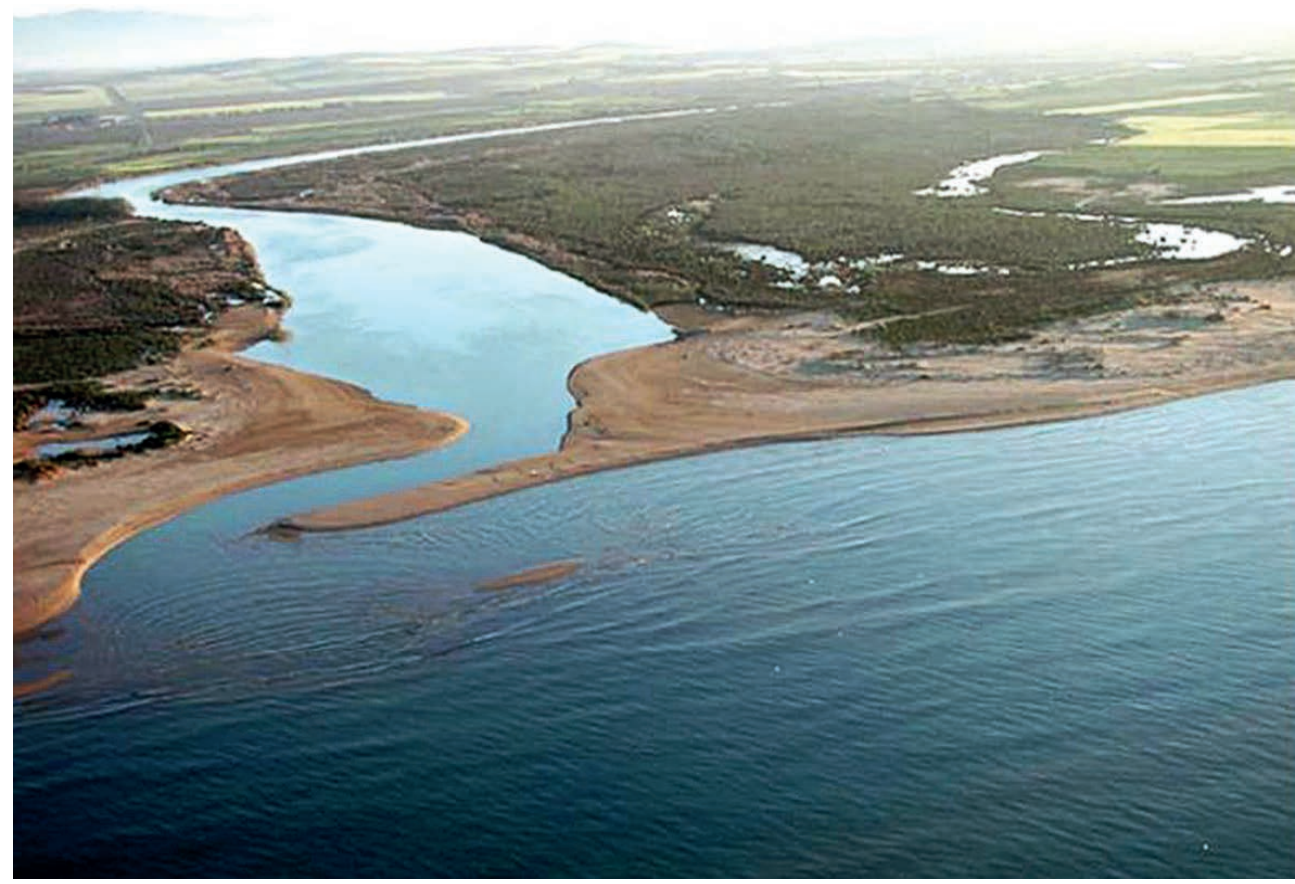

Desembocadura del río Muluya, directamente vinculado a la historia de las islas Chafarinas por su proximidad. 


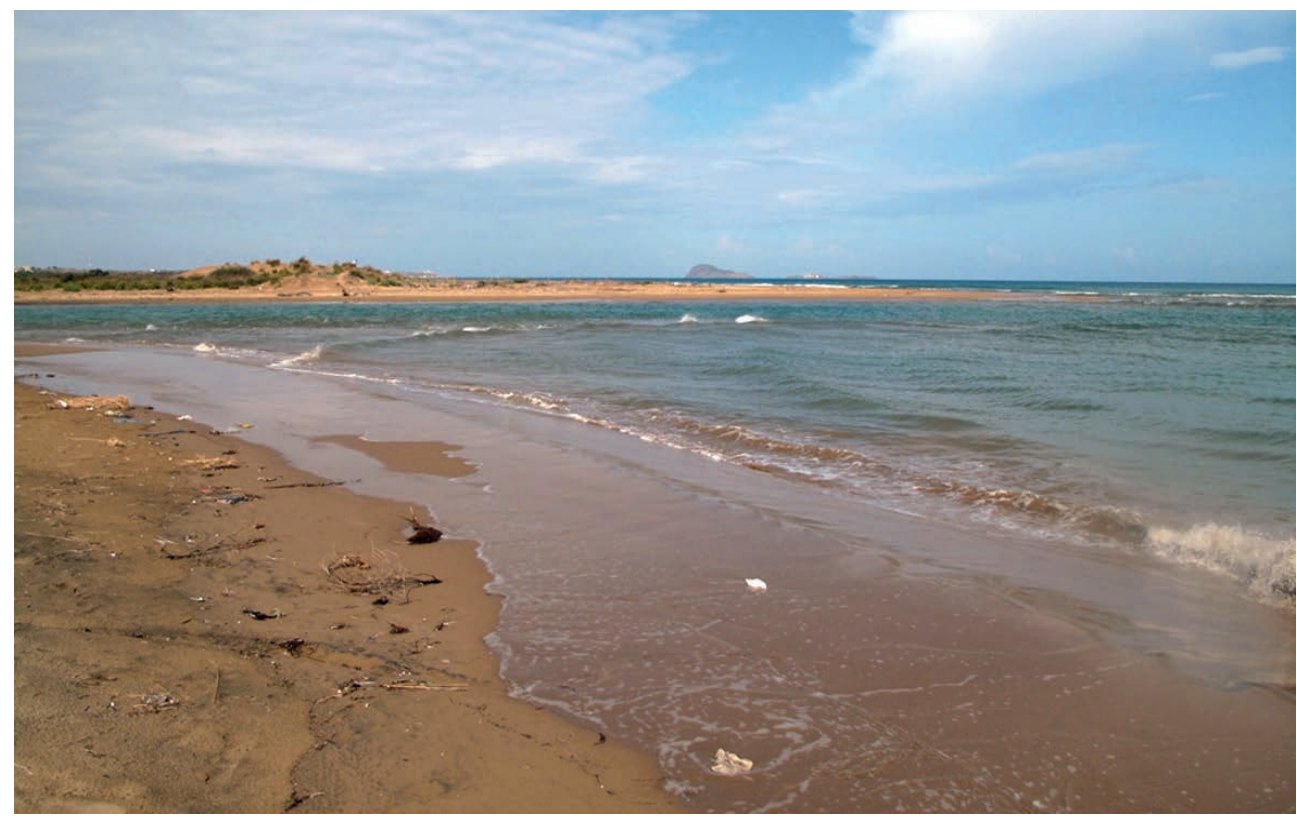

Foto desde la desembocadura del rio Muluya con las islas al fondo.

Un ejemplo de este pa trón de asentamiento también lo tenemos en el islote de Rachgoum (Argelia) frente a la desembocadura del ríoTafna, cercano al antiguo oppidum de Siga, a 47 millas al este del archipiélago de las islas Chafarinas. Este islote tiene una longitud similar a la isla del Rey pero con el doble de superficie y aunque más cercana a la costa, sus condiciones por tuarias eran de mayor dificultad. A pesar de ello las excavaciones arqueológicas desarrolladas a mediados del siglo pasado, sacaron a la luz restos que remontarían su ocupación al siglo VII-V a.C.

El Periplo de Scylax, un derrotero que recogerá en el siglo IV a.C. información de las costas alrededor del Mediterráneo presenta a las dos ciudades que debieron ser las más importantes de la orilla del sur deAlborán en la antigüedad: Melilla y Takembrit, señaladas como Akros y Siga. Estas ciudades distan entre sí poco más de 72 millas, en una travesía en la cual no se perdería la línea de costa; y a medio camino entre ambas se encontrarían las islas Chafarinas. Por ello posiblemente se mencionaría en fechas tan tempranas al ardhipiélago cuando se indica una isla después de un río, quizás la isla del Congreso, de mayor tamaño, tras pasar el río Muluya y un gran cabo en referencia a Cabo del Agua o Ras el Ma.

Melilla, la antigua $A k r o s$, ubicada a poniente de las islas, es mencionada por 
diferentes autores de la antigüedad como Sc ylax (111), Plinio (V, 18), Mela (I, 29), Ptolomeo (IV, 1, 3) así como en el Itinerar io Antonino (IX, 1). Los restos arqueológicos recuperados en el yacimiento de los jardines de la casa del Gobernador en Melilla, corazón de la antiguaAkros-Rusaddir, confirman el hábitat en el peñón rocoso en época fenicia con materiales que se remontan no solo a finales del siglo VII (T-10.1.2.1), sino que su ocupación también perdura poster iormente, en momentos de dicho periplo, como indican los restos principalmente de ánforas de tipo Ramón T-11.2.1.3. de los siglos V-IV a.C.

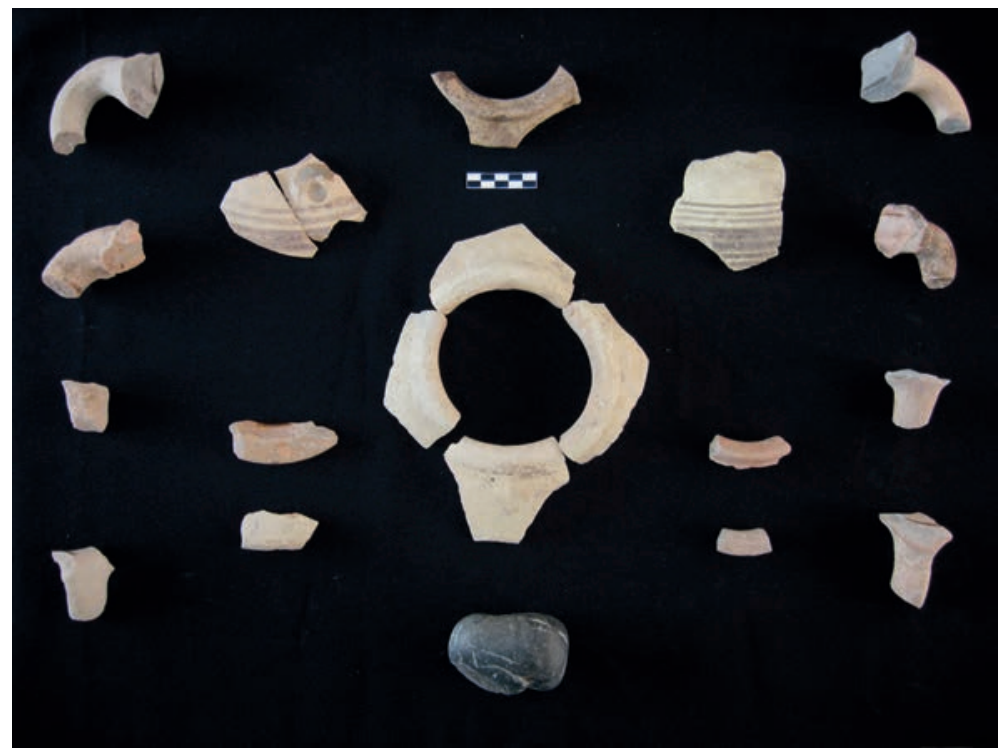

Materiales fenopúnicos de Rusaddir.

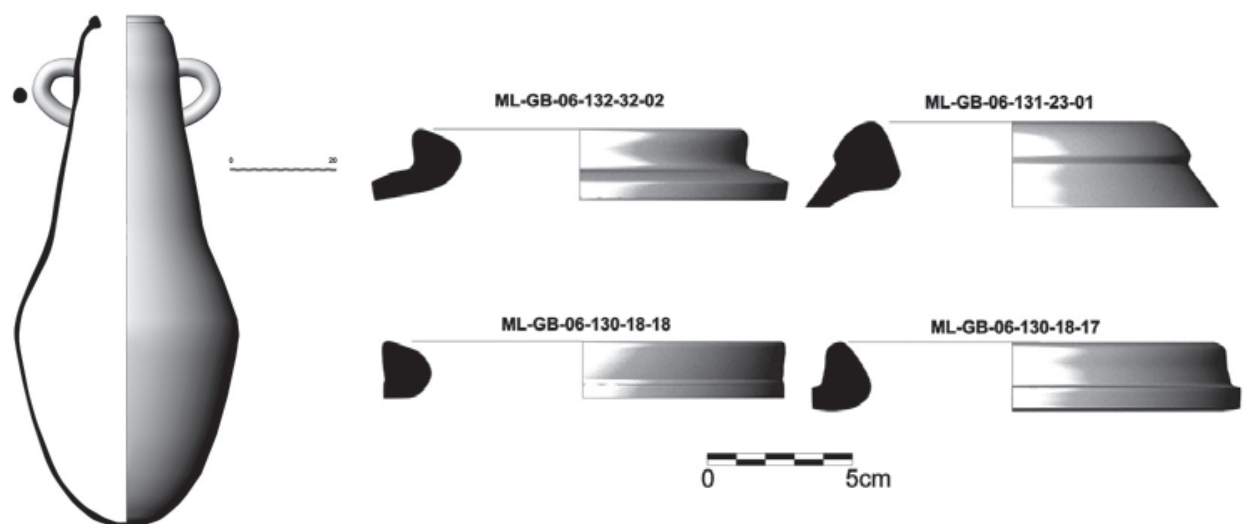

Reconstrucción de ánfora fenicia localizada en Rusaddir. Ánforas feniciopúnicas localizadas en Rusaddir. 
En cuanto a la ciudad de Siga, a levante de las islas, se sitúa en la or illa occidental del río Tafna a $4 \mathrm{~km}$ de su desembocadura. Por las fuentes sabemos que debió ser un enclave frecuentado por malacitanos (Estrabón III, 4-2 y Plinio V, I-46). Es citada por Scylax (111),Tito Livio (XVIII, 17), Estrabón (XVII, 3, 9), Plinio (V, 19) Mela, (I, 5) y en el Itinerario de Antonino (XII, 8; XIII.1) tendría un puerto cercano denominado Portus Sigensis. Estimulada por el establecimiento fenicio del islote de Rac hgoum y de otras localidades como Torre Maure, será capital del reino masaesilio a finales del siglo III a.C . lo que nos ha legado un importante "mausoleo real" de influencia púnica en Beni Rhenane, que llegó a superar los treinta metros.

En este contexto geográfico e histórico entre estos dos enclaves, la condición de fondeadero en la ruta africana permitía a las naves fenicias avituallarse en las islas Chafarinas sin necesidad de fondear en la costa,la cual no siempre garantizaba la seguridad de los mercaderes. También hay que sumar las altas posibilidades piscícolas del arc hipiélago, hecho que pudo pr opiciar un establecimiento pesquero con carácter temporal.

Las referencias más antiguas ${ }^{1}$ relatan las buenas condiciones de amarre de las embarcaciones en las islas e incluso la existencia de agua potable, si bien este último dato es difícil de constatar. Así podemos leer como las islas "forman en la costa una bahía muy capaz y abrigada de todos los vientos, teniendo bastante fondo para cualquier navío de guerra y está muy limpio". Sobre la isla del Cong reso señala que "tiene abrigo de levante, muy seguro par a galeras, pinques y barca en esta según lo que dicen hay agua dulce cavando a cierto paxaje."Acerca del islote de Isabel II afima que "las embarcaciones muy guenas se pueden ar rimar a su costa a medio tiro de fusil tiene cuatro o cinco brazas abrigados del noroeste y este, el sur no les puede dañar pues viene de tan cerca" y finalmente sobre la isla del Rey recoge "tiene dos calas expuestas al este pero cubiertos de todos los demás vientos, estas dos son puestos seguros par a las falucas y fragatillas, sobre la costa de esta isla expuesta al oeste se pueden arimar las embarcaciones de transporte y dar fondo como en la del medio a tiro de piedra de ella y a medio tiro de fusil las de guerra pueden estar con grande seguridad abrigados de todos tiempos".

\footnotetext{
${ }^{1}$ Descripción de la Provincia de Alcalaya. Melilla. 1722.Servicio Histórico Militar
} 


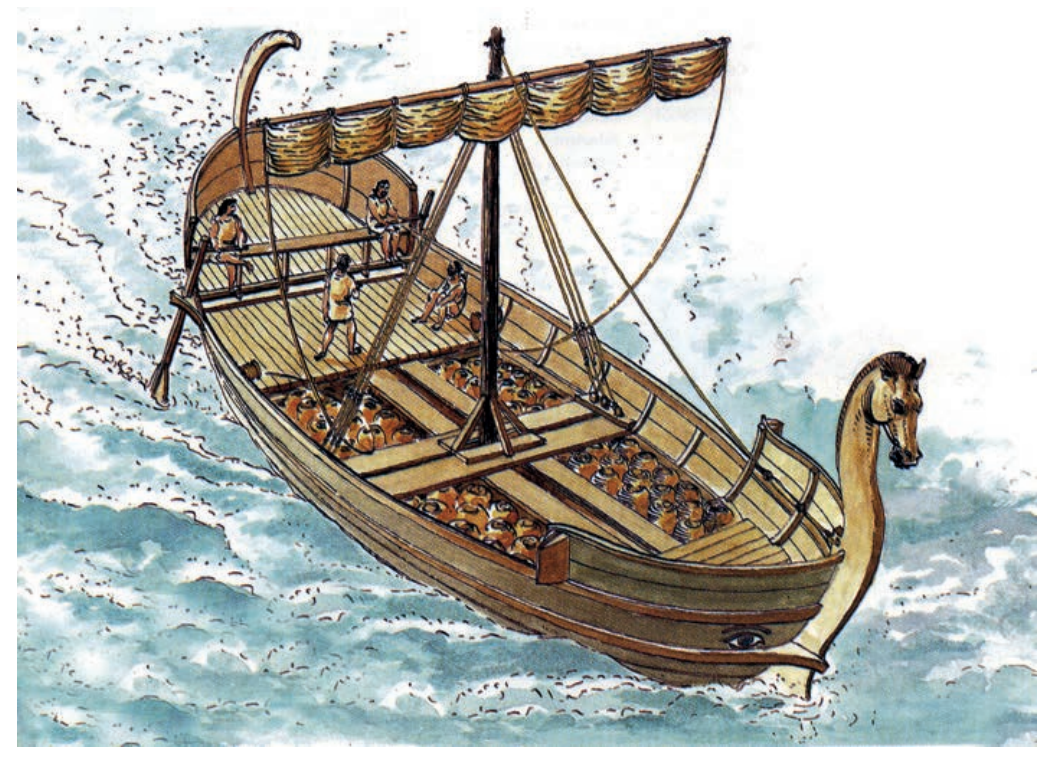

Hippos o barco mercante fenicio

A las óptimas condiciones para el amarre de embarcaciones debe sumarse la excelente posibilidad para la pesca durante todo el añocomo eran sardinas de enero a marzo o bonitos de abril a mayo. En los meses de junio a septiembre la presencia de bancos de aúnidos permitió incluso a principios del siglo XX el uso de almadrabas entre las islas y la costa y finalmente de nue vo en noviembre y diciembre sardinas, aunque en menor pr oporción que en fec has posteriores (Rodríguez, 1910).

Otros datos sobre la riqueza en esta costa no faltan en épocas recientes y así lo podemos ver en los medios escritos ${ }^{2}$ que constatan como una embarcación llegó a sacar una tonelada de pescado y pordlta de medios tuvo que devolverla al mar. Por estas fechas numerosos barcos provenientes de Málaga, Almería o Valencia pasaban la temporada de pesca del bonito o del boquerón de for ma permanente en los caladeros de las islas, y sabemos que al día podían pescarse hasta 4000 piezas, llegando a 800 las que llegará a pescar un barco en una sola jorada, igualmente el atún era ab undante llegando una embarcación a pescar en una jornada entre 1000 y 1500 piezas.

\footnotetext{
${ }^{2}$ El diario ElTelegrama del Rif nos aporta numerosos datos al respecto, en las ediciones de 29 de junio, 27 de julio y 16 de agosto de 1916.
} 


\section{LA PRESENCIA DE CARTAGO Y LA SEGUNDA GUERRA PÚNICA}

Las guerras púnicas enfrentaron a las potencias mediterráneas de Roma y Cartago durante los siglos III y II a.C . De ellas la más conocida fue la Segunda Guerra Púnica (219-201 a.C.) disputada tras poner cerco el general car taginés Aníbal a la ciudad de Sagunto en Iberia, la cual era aliada de Roma.

A la escasez de da tos historiográficos del sur de Alborán, se suman los pocos materiales asociados a este momento en tiempos en que ninguna de las dos potencias quiso desaprovechar la posibilidad de contar con un fiel aliado en tierras africanas. Mauros (Mauritania), masesilios (Numidia occidental) y maselios (Numidia oriental) eran las tres confederaciones tribales más importantes que se repartían entre el actual Marruecos, Argelia y las ciudades españolas de Ceuta y Melilla. Los distintos enclaves mauros y númidas se convertirán en importantes fortalezas que nutrirán al ejército cartaginés y romano en apoyo a la conquista de Iberia. El aguerrido carácter de los norteafricanos llevará a los generales de ambas potencias a contar con mercenarios de esta región para sus enfrentamientos, en unas tierras inhóspitas de por sí, el juego de alianzas incentivará la lucha de estas confederaciones tras ser agasajados con obsequios y pr omesas por las distintas delegaciones que harán cambiar el apoyo de un bando a otro. Sin duda el archipiélago de las islas Chafarinas debió erigirse como un lugar importante de control marítimo en estos momentos, donde la ruta de ida a la Península iniciada en Cartago (Túnez) pasaba por Qart Hadasht (Cartagena) y posteriormente Gadir (Cádiz) pero tenía su regreso por las costas africanas.

De estas fechas tenemos escuetas menciones del $r$ eino amazighen de Mauritania que se extendía desde el océano Atlántico hasta el río Muluya. Las fuentes nos señalan la existencia de un r ey llamado Baga de Mauritania, el cual prestará auxilio al rey masilio Masinissa con 4.000 mauros en el año 204 a.C . para cruzar a sus dominios tras la vuelta de Iber ia, después de traicionar los intereses cartagineses estableciendo una alianza con Comelio Scipión (Livio XXIX, $30,1)$. Esta escolta acompañó al rey a sus dominios refugiándose en las poblaciones existentes en su trayecto entre las que estaría Rusaddir, que en estos momentos gozaba de buenas infraestructuras, siendo cabeza de la región. Tras una posición inicial a favor de Cartago, el rey masilio Masinissa se convertirá en aliado del pueblo romano por lo que conseguido su apoyo, Tito Livio en su Historia de Roma, nos cuenta como el general Cor nelio Scipión intentará atraer a la causa romana de nuevo a Syphax, rey masesilio. 
Los Massaesyli era una importante confederación al otro lado del río Muluya entre el reino mauro y el de los Massaeli, tenía por capital la ciudad mencionada de Siga en la actual Takembrit (Beni Saf, Argelia) ocupando un tercio de la actual Argelia y probablemente parte oriental de Marruecos. Dos jor nadas a caballo bastarían para unir Cabo deAgua (Ouxda, Marruecos) frente a Chafarinas con la capital a poco más de cien kilómetros. Syphax exigirá la presencia de Scipión en plena Segunda Guerra Púnica en Siga para sellar dicho acuerdo. Scipión partirá con dos quinquerremes hacia África produciéndose el encuentro con la flota de Asdrúbal que regresaba tras su fracaso de Iberia aunque ambos generales no se enfrentarán al ser un puerto neutral, si bien para entonces parece que la decisión de apoyar a Cartago era inamovible (Livio XVIII, 17 y 18), palpándose el interés de romanos y cartagineses por establecer alianzas con los soberanos de esta oilla africana. Dicha tribu será derrotada por la confederación vecina de los Massaeli al mando de Masinissa, unificando ambos r einos en uno tras la Segunda Guer ra Púnica denominado Numidia, trasladando la capital a Cirta (Constantina, Argelia), que se extendía desde el río Mulug hasta Cartago, en connivencia con Roma.

Entre los hallazgos más significa tivos de este per iodo cabe mencionar el efectuado hace tr einta años en Melilla for mado por un conjunto de miles de monedas, principalmente de cobre y electrón (aleación de oro y plata), siendo su cronología del 221-202 a.C. Éstas corresponderían a un último intento de Catago por reforzar su poder en Iber ia en el que difer entes flotas acudirían en auxilio con mercenarios reclutados durante sus escalas en territorio africano.

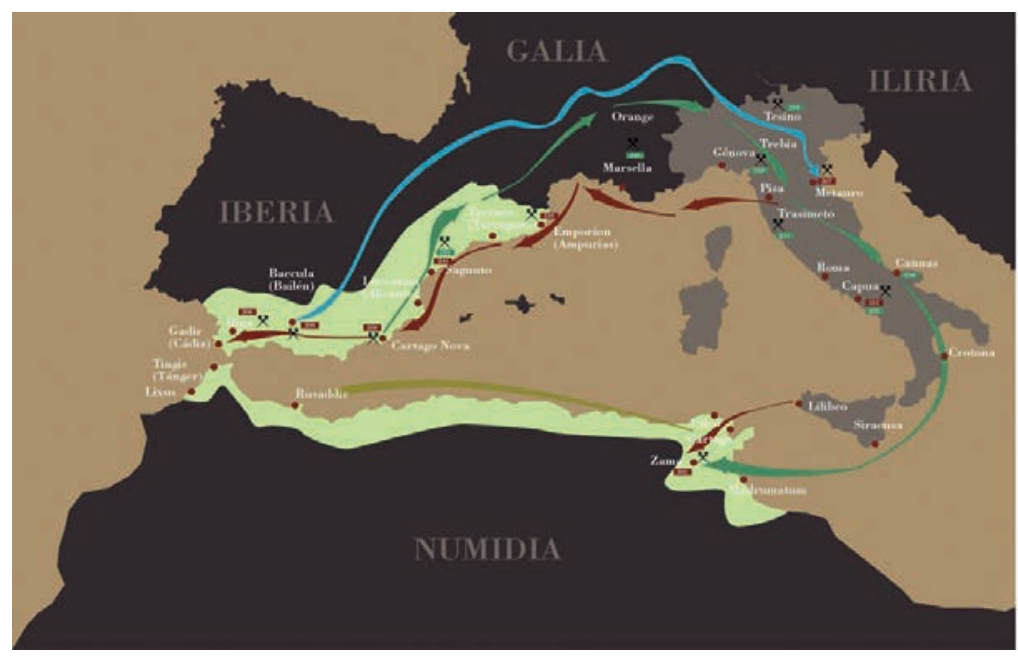

II GUERRA PÚNICA

La Segunda Guerra Púnica.

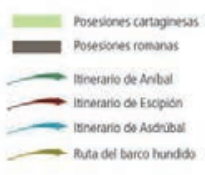



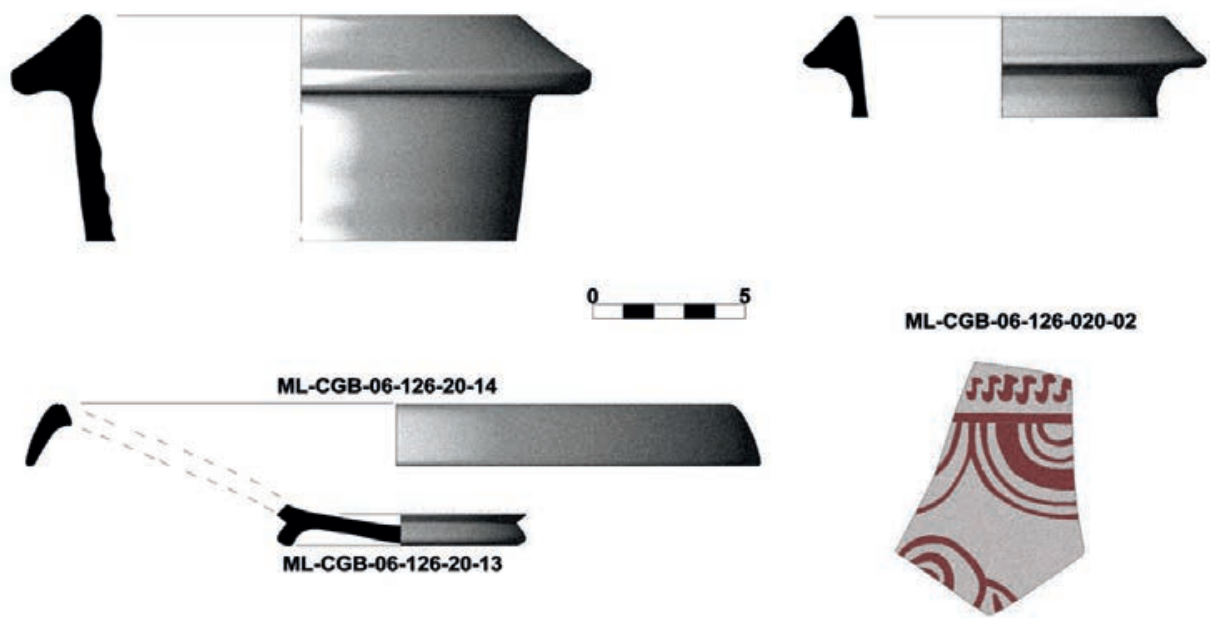

Restos de ánforas grecoitálicas y materiales íberos.

El volumen de intercambios comerciales en el álea del sur deAlborán por causas vinculadas a la ocupación $\mathrm{r}$ omana de Gadir (206 a.C.) se verá reducido considerablemente. Esta urbe sería el principal centro dinamizador de esta orilla, aunque también pueden rastr earse productos netamente car tagineses en Melilla durante el siglo II a.C como son las conocidas ánforast-5.1.1.1,T-7.4.2.1 y T-7.4.3.1, envases de procedencia tunecina que son fr ecuentemente localizados en las distintas exca vaciones. Otros recipientes correspondientes a estos momentos serán las ánforas grecoitálicas, imitadas en los centros alfareros de la vieja Gadir (Cádiz), localizadas en diferentes zonas de la antigua Rusaddir como son Plaza de Armas o Casa del Gobernador.

Concluido el enfrentamiento entre ambas potencias mediterráneas tras la decisiva batalla de Zama enTúnez (202 a.C.), Roma resultará ser la única vencedora, si bien Car tago no fue ar rasada tras la Segunda Guer ra Púnica y sus conexiones con los enclaves portuarios de la costa africana continuarán medio siglo más, libres de control romano, hasta su destrucción en el 146 a.C. fecha en que la navegación quedaría a merced de los navegantes latinos. Roma como muestra de lealtad confirmará a Masinissa como rey de una gran Numidia formada por su antiguo reino masilio y parte del masesilio confiscado a Siphax,que morirá en el año 203 a.C., siendo nuevamente el río Muluy a con toda probabilidad el que constituía la frontera con el reino de Mauritania. 


\section{MAUROSY NÚMIDAS BAJO LA ÓRBITA DE ROMA}

Con el nuevo orden generado tras la Segunda Guer ra Púnica, el Muluya nuevamente constituía la frontera de los reinos bereberes de Mauritania y Numidia. Del lado Mauro sabemos los nombres de los diferentes reyes, caudillos guerreros cabeza de las confederaciones tribales como Baga, Bochus o Bogud, donde las ciudades gozarán de amplia autonomía. Un territorio ajeno según las fuentes a Roma hasta finales del siglo II a.C. en el que los acontecimientos acaecidos en la conocida como Guerra deYugurta nos presentan las desventuras del rey númida y su enfrentamiento con la república romana siendo la zona del Muluja citada con frecuencia.

Deberá pasar un siglo para volver a localizar en las fuentes noticias de los reyes mauritanos, refiriéndose a los sucesos deBocchus I (118-80 a.C.) y su papel en el enfrentamiento del reino vecino de Numidia con Roma, en el que la región del Muluya jugaría nuevamente un importante papel estratégico.

Tras morir Masinissa, el reino de Numidia fue dividido entr e sus hijos, quedando Micipsa, a la muerte de sus hermanos como único gobernante.Yugurta era el sobrino de éste y fue adoptado ante la simpatía despertada tras las luchas en Numancia a favor de los romanos, apoyado por Scipion Emiliano tal como nos narrará Salustio en su Bellum Iugurthinum, antiguo procónsul de Numidia medio siglo después de los acontecimientos.

Yugurta, a la muerte del soberano, intentará quedarse con el territorio y tras asesinar a su hermanastro se verá obligado a repartir Numidia con uno de los herederos de Micipsa que buscará protección de Roma. En el año 112 a.C invadirá Numidia oriental y asediará la capital Cirta (Constantina, Argelia) que tras un largo asedio masacrará a la colonia de itálicos motivando que Roma le declarara la guerra.

Finalmente las conversaciones con Bochus de Mauritania por par te del general romano Sila para traicionar a Yugurta serán las que den por finalizado el conflicto en el 104 a.C. obteniendo por dicha acción parte de la Numidia occidental, sobrepasando sus dominios el río Muluya.

Aunque fuentes clásicas como la del histor iador griego Polibio señala la ausencia de relaciones entre la república romana y las distintas ciudades del estrecho (Pol. 16, 7, 29), la llegada de comerciantes hispanos e itálicos a esta costa se intensificaría a mediados del siglo II a.Creactivándose los intercambios tras la caída que provocaría la Segunda Guerra Púnica. 


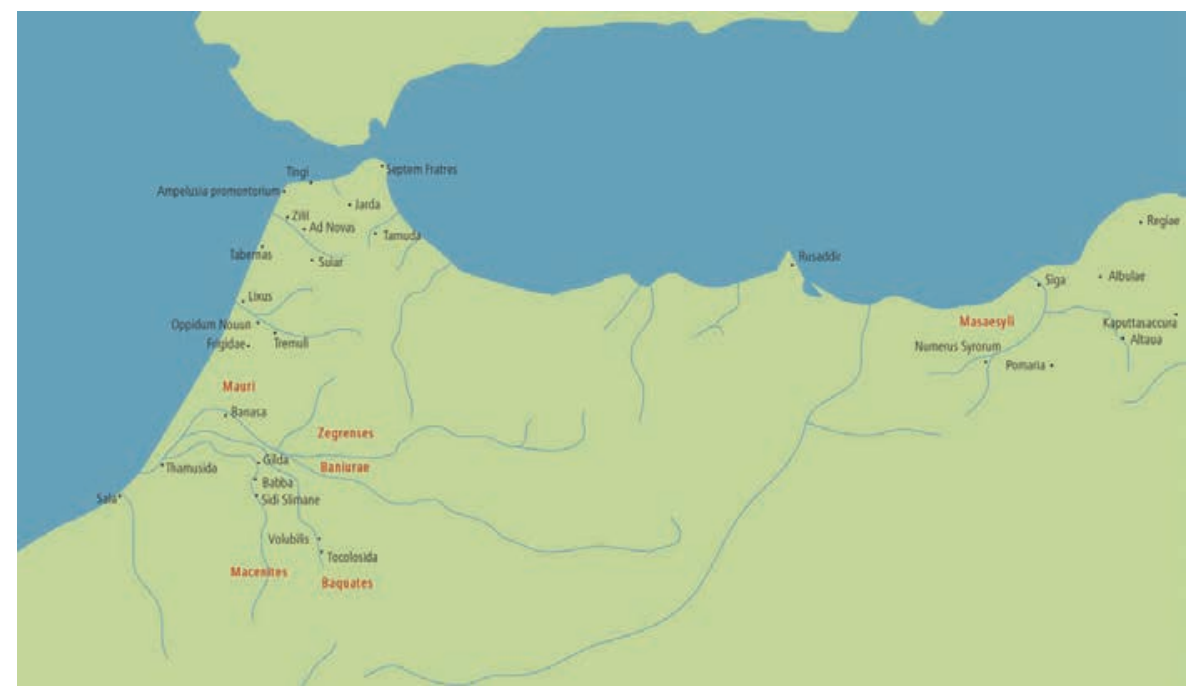

Poblaciones del Rif

Entre los envases contenedores que aparecen en las excavaciones destaca la pervivencia de modelos de tradición púnica del entono de Gadir (T-12.1.1.1.) que acentúan la continuidad de la pr oducción del área del círculo del Estrecho, potenciada tras la ocupación de la ciudad de Cádiz por las tr opas romanas. Dichos envases contenían principalmente salazones, un producto de gran fama y calidad, cuya producción está documentada en diferentes talleres de Cádiz pero también en la orilla africana en la ciudad de Kuass (Asilah).

La guerra deYugurta (112-105 a.C.) marcará un punto de inflexión entre las relaciones de Roma con Mauretania las cuales no debieron ser muy intensas con anterioridad a juzgar por los datos arqueológicos o las fuentes clásicas como Salustio, que señalaría la ausencia de contactos con anter ioridad a esta guer ra entre ambos pueblos "Sobre todos los mauros mandaba el rey Boco que no conocía del pueblo romano más que el nombre. Tampoco nosotros lo conocíamos antes ni en paz ni en guerra" (Salustio, XIX, 124.)

En la región de Quebdana se advertirá esta tímida penetración de los distintos productos. Bochus I de Mauretania potenciará las ciudades costeras de su territorio concluida la guerra estableciendo una estrecha alianza con Roma, tras traicionar a su cuñado a cambio de una extensa franja de ter ritorio pasado el Muluya, política seguida por su hijo Mastenososus (80-49 a.C.).

En la antigua Rusaddir estas transfor maciones se advertirán en el sustancial incremento demográfico, la urbanización del promontorio y la participación 
activa en las redes comerciales distribuyéndose vajilla de mesa de barniz negro, los ungüentarios de tipo fusiformes o las lucernas delfiniformes Ricci G. como debió suceder en el resto de los enclaves.

La demanda de estos pr oductos debió ser m uy solicitada en esta or illa procedente de ciudades hispanas en un intenso pr oceso de asimilación de las modas romanas, especialmente de Gades (Cádiz) y Cartago Nova (Cartagena), ciudades tradicionalmente vinculadas desde época fenicia con la æogión que pervivirán en épocas posteriores a juzgar por las fuentes.

Igualmente se observa la intensificación de la impor tación de productos alimenticios como las salsas de pescado y vino, productos envasados en ánforas facturadas en el entor no de la antigua Gadir ahora Gades, en pleno proceso de aculturación romana, que reproducen por un lado los tipos de tradición cataginesa (T-7.4.3.2 y T-7.4.3.3.) y por otro las formas itálicas (Dressel 1) en un proceso de hibridación económica, distribuyéndose en el sur deAlborán de forma simultánea ambos tipos hasta el último cuarto de siglo I a.C.

Precisamente el pecio Escombreras II, localizado en la vieja Carthago Nova (Cartagena), debió participar en la redistribución africana de productos romanos con capacidad para miles de ánforas,localizándose en su carga ánforas Dessel 1 del mismo modelo a las localizadas en Rusaddir , en la costa de Sebja de BuAreg (La Bocana, Nador) o en Tres Insulas (Chafarinas), así como cerámica de barniz negro y lucernas.

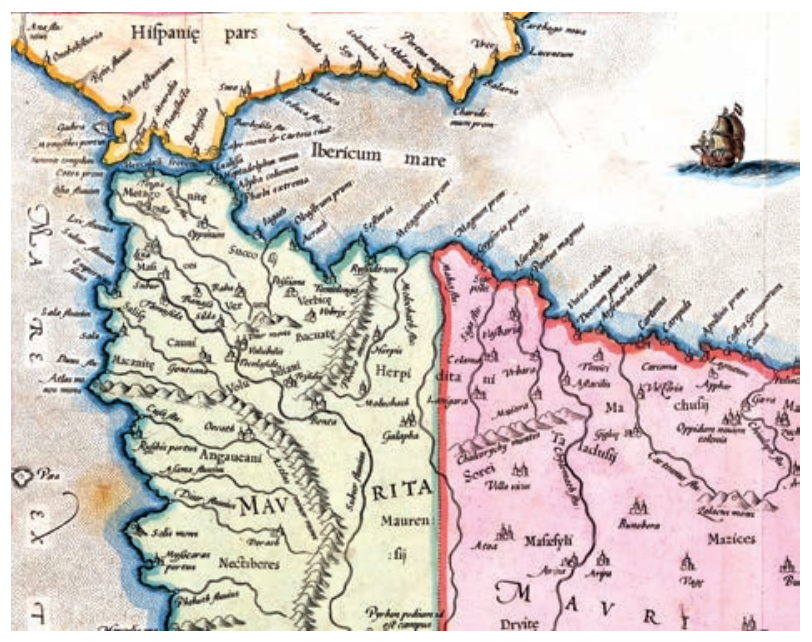

Mapa de las Maunitanias de Mercator.

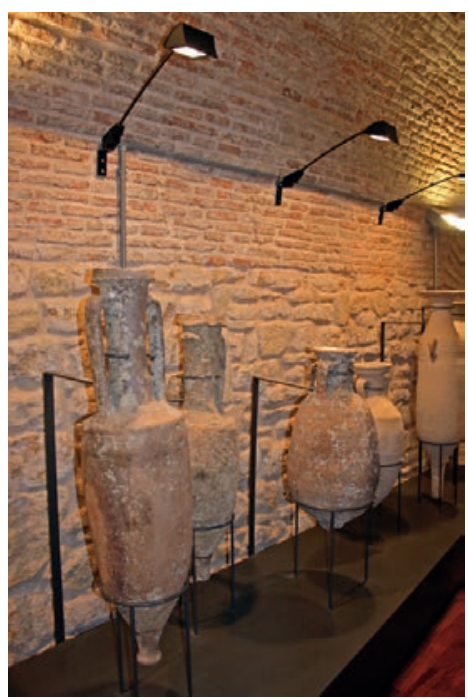

Áforas Dressel 1 localizadas en el mar. 


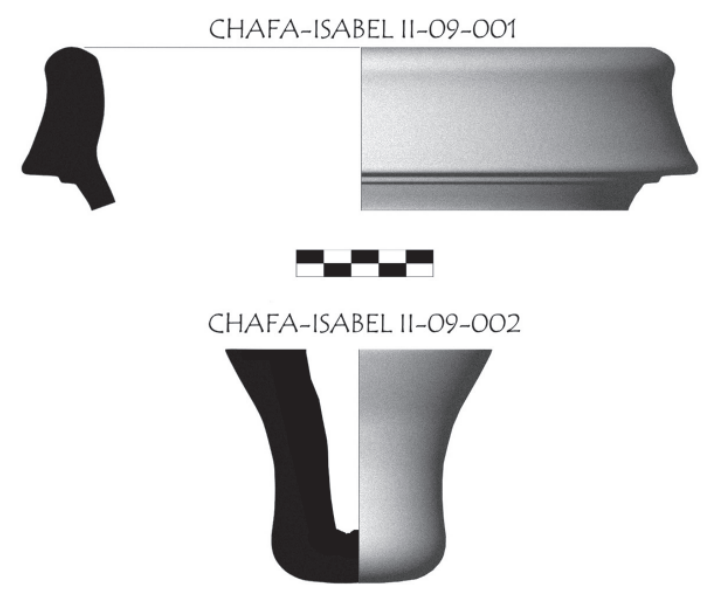

Ánforas romanas localizadas en la isla de Isabel II.

En el transcurso del "Proyecto de catalogación, clasificación y digitalización de obras públicas y privadas sitos en los archivos nacionales” ${ }^{3}$, en el cual se preveían prospecciones para localizar restos de edificaciones desaparecidas en la isla de Isabel II, fue localizado un piote de ánfora junto a la antigua Iglesiaactualmente en un lamentable estado. Tras la localización de los primeros fragmentos observamos que varias parcelas de tierra habían sido removidas para practicar fosas donde se entierran los residuos orgánicos de la guarnición y al analizar las distintas terreras fue recogido un nuevo ejemplar.

Los fragmentos de ánforas romanas localizadas en estas prospecciones, aunque en un númer o poco significativo, abren nuevas vías de in vestigación de este periodo en las islas y su entomo. El primer fragmento localizado corresponde a un pivote de ánfora republicana del tipo Dressel 1 mientras que el segundo fragmento se trataba de un borde de este mismo tipo, variante A. El tipo Dressel 1 es uno de los envases más estudiados del mundo romano, por lo general estas ánforas tienen poco más de un metro, con labios inclinados y asas largas con hombros bien marcados. Este envase en origen vinario, sería producido en la zona de Campania y Etriria y reproducido con posterioridad en el litoral meridional hispánico, principalmente el área de Cádiz y Algeciras. Su pasta es mar rón con tonalidad rojiza y tiene una morfología muy característica siendo la sección del borde tr iangular, la pared se

\footnotetext{
${ }^{3}$ Convenio suscrito con el Organismo Autónomo de Parques Nacionales.
} 
recubre de engobe amarillento para sellar los poros, dejando entrever las partículas negras de la pasta. En esta zona no se han constado construcciones tras el estudio de la planimetría histór ica que hayan alterado sustancialmente la zona por lo que es previsible que existan mayores restos en el área. Tras estos primeros hallazgos, fueron proyectados nuevos trabajos de in vestigación arqueológica que preveían varios sondeos planificados para el año 2010, pero fueron suspendidos de forma indefinida por falta de autor ización para poder excavar. Sus resultados hubieran aportado mayor luz a este capítulo.
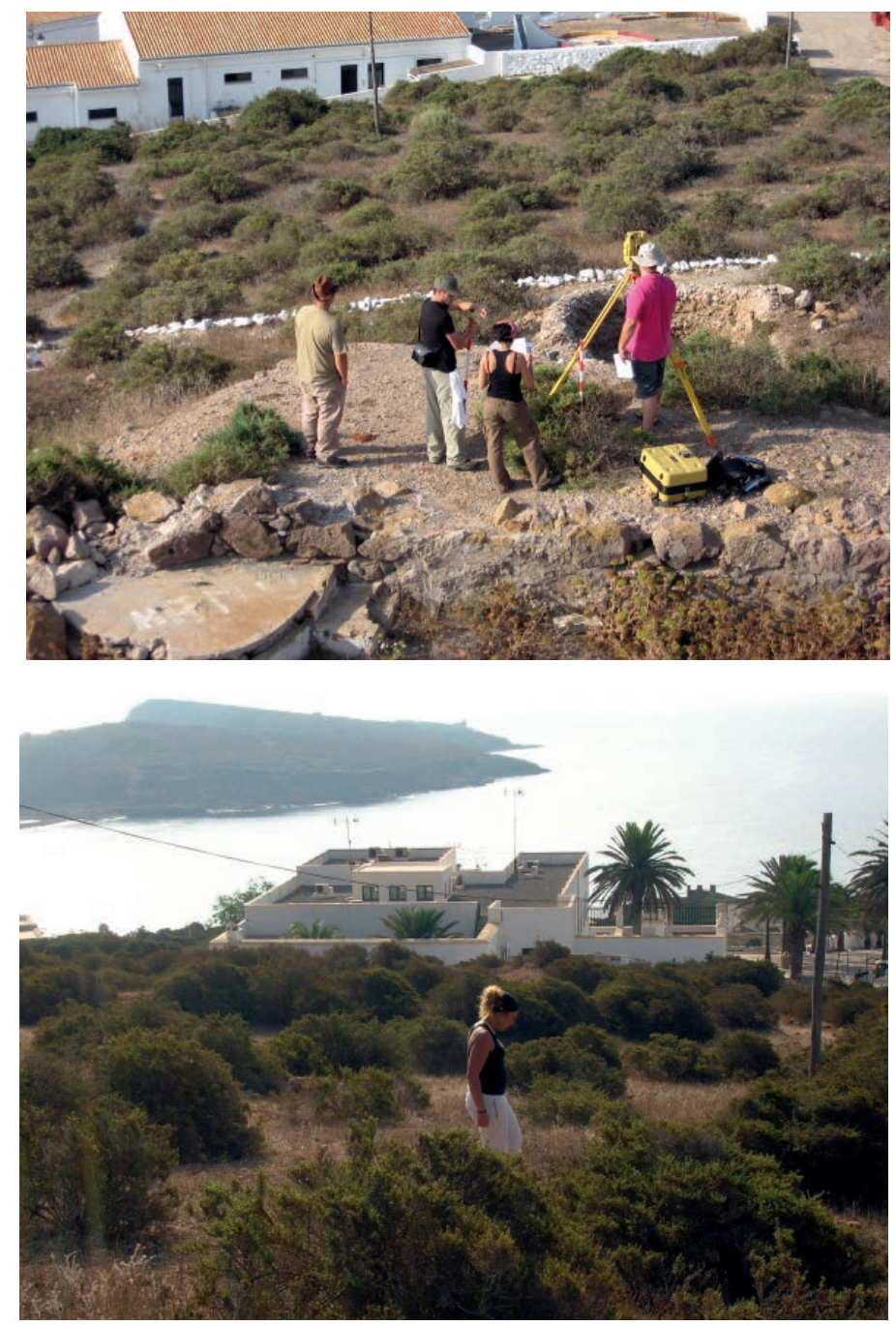

Prospecciones y toma de datos en diferentes sectores de la isla de Isabel II 
La circulación de estos envases vinarios entre el caboTres Forcas y las islas Chafarinas queda ampliamente documentada, destacando por el alto número de intervenciones realizadas la antigua Rusaddir, que gozaría de la capitalidad de la Mauritania oriental. Entre los hallazgos en Melilla destaca el cero de San Lorenzo, Plaza de Armas, Parque Lobera, Plaza García Morato o Casa del Gobemador. En el yacimiento de Gobernador aparecen los primeros ejemplares asociados a niveles de finales del siglo II a.C. junto al tipo RamónT-7.4.3.3. conocidas como Dressel 18 en el siglo pasado interrumpiéndose la llegada de ánforas gecoitálicas, forma de las cual deriva.

En el mar conocemos varios hallazgos, frente a la costa del cabơres Forcas a mediados de los sesenta fue recuperado un envase de esta tipología por la embarcación de pesca" El Carburante” y otro tipo similar fr ente a la Mar Chica a veintiséis metros de profundidad, por la embarcación de pesca“" La Bicicleta”. Actualmente varias de estas ánforas se encuentran expuestas en la sala Mauros y Romanos en el Museo de Arqueología e Historia de la ciudad de Melilla, existiendo otra pieza de este modelo en la Cámara de Comercio de Melilla.

Tras la muerte de Bochus I (80 a.C.) el reino de Mauretania será dividido entre sus dos hijos Bogud y Bochus II, siendo nuevamente el río Muluya el eje divisorio entre ambos reinos. Los territorios al oeste del reino le correspondieron a Bogud (49-38 a.C.), mientras que las tierras al este de dicho río pasaron a Bocchus II (49-33 a.C.). Durante las segunda guerra civil romana ambos reinos serán aliados de Julio Cesar.

Bochus II atacará Numidia, aliada de Pompeyo, obligando a Juba I a dividirse en dos frentes. Tras su derrota en Tapso (Ras Dima) como agradecimiento por parte de Cesar ampliará sus ter ritorios hacia el este hasta las proximidades de Cirta (Constantina). Poco después la extensión occidental de su reino vendrá justificada durante la tercera guerra civil aprovechando una revuelta en la ciudad de Tingi (Tánger) y su región contra el rey mauritano Bogud, el cual se hallaba luchando con los partidarios de Marco Antonio en la península. Este momento será aprovechado por Bochus II aliado ahora de Octaiano para ocupar el teritorio en el año 38 a.C. y unificarlo.

La costa de Quebdana debió ser una de las pr imeras regiones situada en la frontera, marcada por el río Muluy a, y especialmente Rusaddir que por entonces sería cabeza del reino de Bogud. No sabemos si su ocupación sería de foma violenta pero la existencia de niv eles de abandono a comienzos del siglo I a.C . podría 
delatar el despoblamiento rusaditano en fechas cercanas a la contienda si bien será la arqueología la que nuevamente nos permita en el futuro obtener más datos.

A la muerte sin herederos de Bochus II, en el año 33 a.Ç las dos Mauritanias (oriental y occidental) serán legadas en herencia a Roma permitiendo un nuevo impulso a la integración de la región en los modos de vida romanos, perdurando determinados usos y costumbres de origen fenicio como la lengua.

\section{LA HEGEMONÍA DE ROMA EN LOS ANTIGUOS REINOS BEREBERES}

Tras la muerte del último rey mauro Bochus II en el 33 a.C. Roma establecerá el control directo del reino mientras que en Numidia repondrá en el trono (29-25 a.C) al númida Juba II. Su padre Juba I (50-46 a.C.) rey de Numidia se suicidó tras perder en Tapso (Ras Dima) contra Julio Cesar durante la contienda con Pompeyo. Muerto su padre será adoptado por César y educado en Roma y a su muerte protegido de Octaviano. El rechazo de Juba II por la pob lación del reino de Numidia hará que pase a ser administrada de foma directa, compensando a éste con la entrega de Maur etania (25 a.C.-23 d.C.) y pocos años después contraerá matrimonio con Cleopatra Selene, hija de Marco Antonio y Cleopatra.

La capital será trasladada a Iol que pasará a llamar se Cesarea (Cherchel, Argelia) y como señala Pomponio Mela desconocida en otro tiempo y afamada a raíz de este hecho (Mela I, 5 30) compartiendo con Volubilis la capitalidad regia. Durante el reinado de Juba II y su hijo PtolomęRoma controla de manera efectiva el reino mauretano bajo una aparente independencia implantando numer osas colonias para los veteranos de guerra.

Los restos localizados en la isla de Isabel II incidirían en la existencia de un establecimiento en dicha isla para el r esguardo de naves en la activ a dinámica costera especialmente en el momento queIol-Cesarea (Constantina) es capital de Mauretania con Juba II (50-23 a.C), lugar donde fue localizada una moneda de Rusaddir.

A finales del siglo I a.C. la diversidad morfológica de los envases de momentos anteriores será suplida casi exclusivamente por las ánforas tipo Lomba do Canho 67, la cual fue penetrando en el mercado decenios antes, en estas fechas la urbanización de las ciudades costeras sufrirá una profunda reestructuración, ahora bajo dominio de Roma. Este tipo de ánfora es fr ecuente en los 
últimos niveles de ocupación en el yacimiento de Casa del Gobernador (Melilla) y marcarían, sino su abandono definitivo, su ocaso.

En el año 40 d.C. el último rey de Mauretania, Ptolomeo, muere asesinado y se inicia una ocupación efectiva del territorio mauro no exenta de dificultades. El río Muluy a en el siglo I dividirá las pr ovincias de Maur etania Tingitana y Mauretania Cesariense en época de Claudio (10 a.C.-54 d.C.) con capital en Tingi (Tánger) y Cesarea (Cherchell). En estos momentos Pomponio Mela (I, 5, 39) mencionaría las dos ciudades de pequeño tamaño llamadas Rusgada (Melilla) y Siga (Takembrit) y entre ellas el Muluya como límite de reinos en otro tiempo.

En el cambio de era, la impor tación de productos béticos se realizará en ánforas de salazones Dressel 7-11, que por ser su número escaso en proporción a otros tipos anfóricos de cronología anterior, cabe pensar que marcarían una caída de las impor taciones y anunciaría el fin de Rusaddir y probablemente un impacto negativo en toda la región de Guelaya y Quebdana. En estos momentos la sustitución de vajilla de bar niz negro por sigillatas y el cambio de los ungüentarios fusiformes de tradición púnica al de bulbo romano son reflejo de la penetración en el mercado de nuevos productos netamente romanos que gozarían de gran aceptación, aunque no siempre tan bien representados en los yacimientos de la región como lo son los productos de momentos anteriores.

El geógrafo, matemático y astrónomo Claudio Ptolomeo en el siglo II d.C. recogerá en trece libros un gran tratado de astronomía y será en su libro octavo sobre Geographia donde describirá el mundo conocido, señalando las coordenadas geográficas de numerosos enclaves incluyendo algunos en tomo a las islas Chafarinas. Entre las ciudades y puntos geográficos recogidos destacan

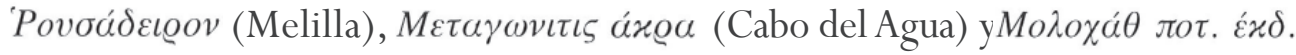
(desembocadura Muluya) (Ptot. IV, 3) señalando que la tribu que habitaba en la región de la costa y el interior del Muluya eran los Herpeditani (Ptol. IV, 1, 5; IV, 2, 5).

El itinerario de Antonino fue un documento del siglo III d.Cque describía las rutas más importantes del imperio romano, indicándonos los lugares de avituallamiento o reposo (mansio) así como las distancias que existían entre ellos en dos rutas terrestres y una marítima. En el itinerar io provincial marítimo que recogía numerosos fondeaderos aparece como último lugar de la Tingitana un fondeadero ubicado "junto a las tres islas, Ad Tres Insulas" (Itin. Anton. 11, 5) enclave que debió ubicarse, en principio, en Cabo del Agua- Ras El Ma. 


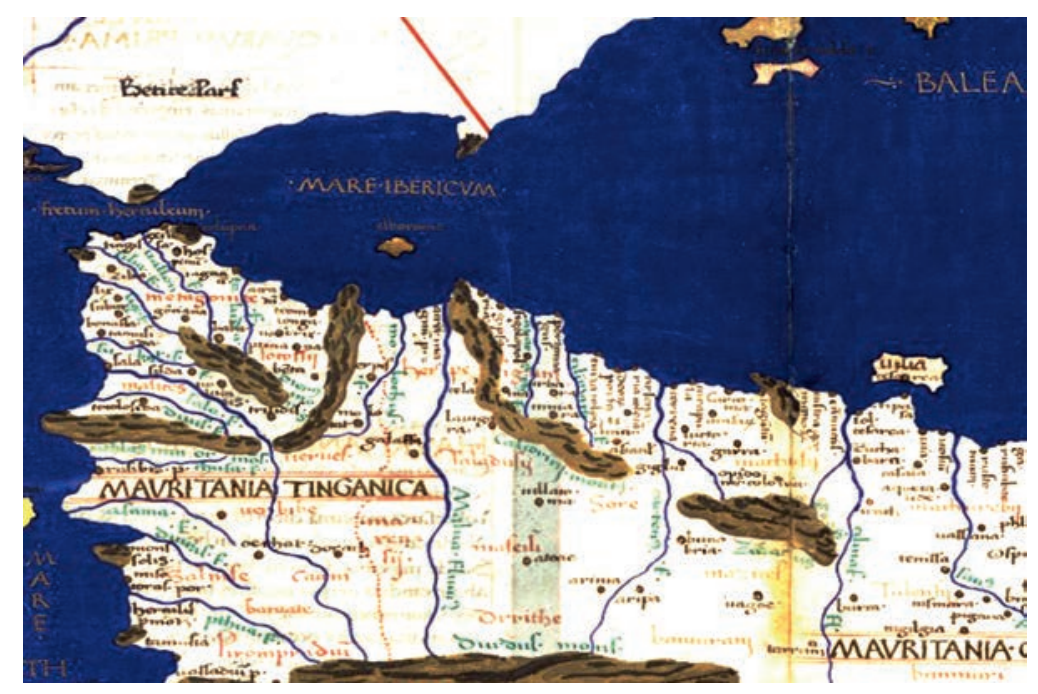

Cosmografía de Claudio Ptolomeo (1467).

El uso del substantivo acusativo Ad indica cercanía a un lugarseñalando “al lado de”. Es habitual señalar las mansiones según algún hito geog ráfico ante la ausencia de núcleos urbanos. La región inhóspita que representaba la zona de Quebdana llevaría al establecimiento de un lugar para avituallamiento y descanso de los viajeros así la referencia de su ubicación lógicamente no podía ser otra que la hospedería o mansio al lado de las tres islas.

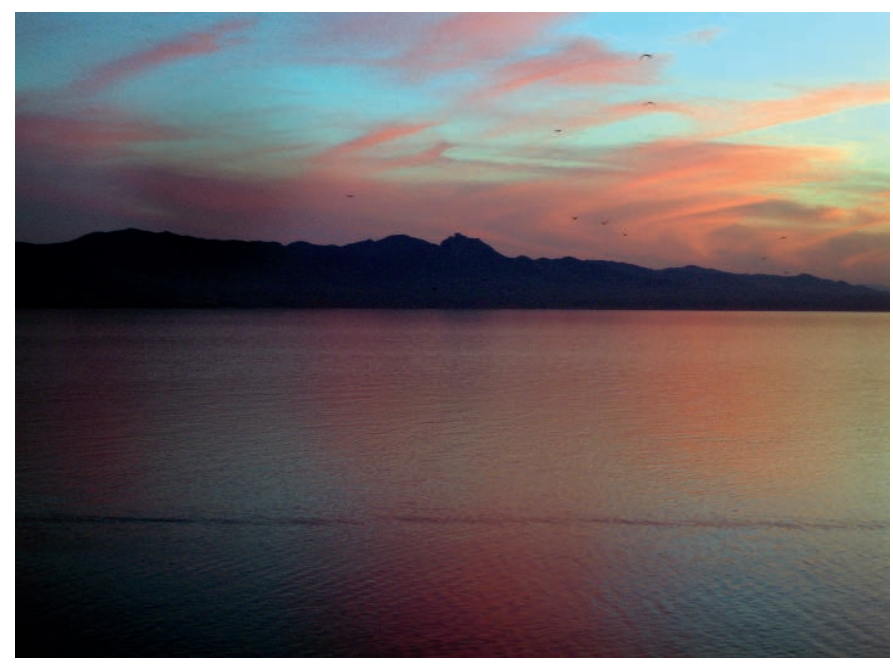

Perfil de la región Quebdana visto desde el archipiélago de las Chafarinas. 
El itinerario recoge la existencia de puer tos intermedios entre la capital maura, Tingi y el límite de su povincia, señalando entre los distintos lugares para fondear Rusadder colonia, la actual Melilla.Desde el puerto rusaditano se retomaría el trayecto a las cercanías de Chafarinas ubicado a $L X V$ millia passuum (mil pasos correspondían a 1480 metros) distancia errónea salvo que fueran recorridos de ida y vuelta pues correspondería a poco más de 96 kilómetros distando en realidad unas 25 millas (50 kilómetros aproximadamente).

El siguiente fondeadero sería el conocido por Flumen Malua antes de entrar en la provincia romana de la Caesariensis, seguramente en la desembocadura del actual río Muluya pero no debería descartarse el río Kiss, si bien vuelve existir un error al doblar la distancia verdadera. No obstante la existencia de un fondeadero oficial en Cabo delAgua o Ras el Ma no impide la posibilidad de que existieran otros de menor entidad en las islas Chafarinas pues como ha quedado confirmado, existen materiales arqueológicos del siglo I a.C.

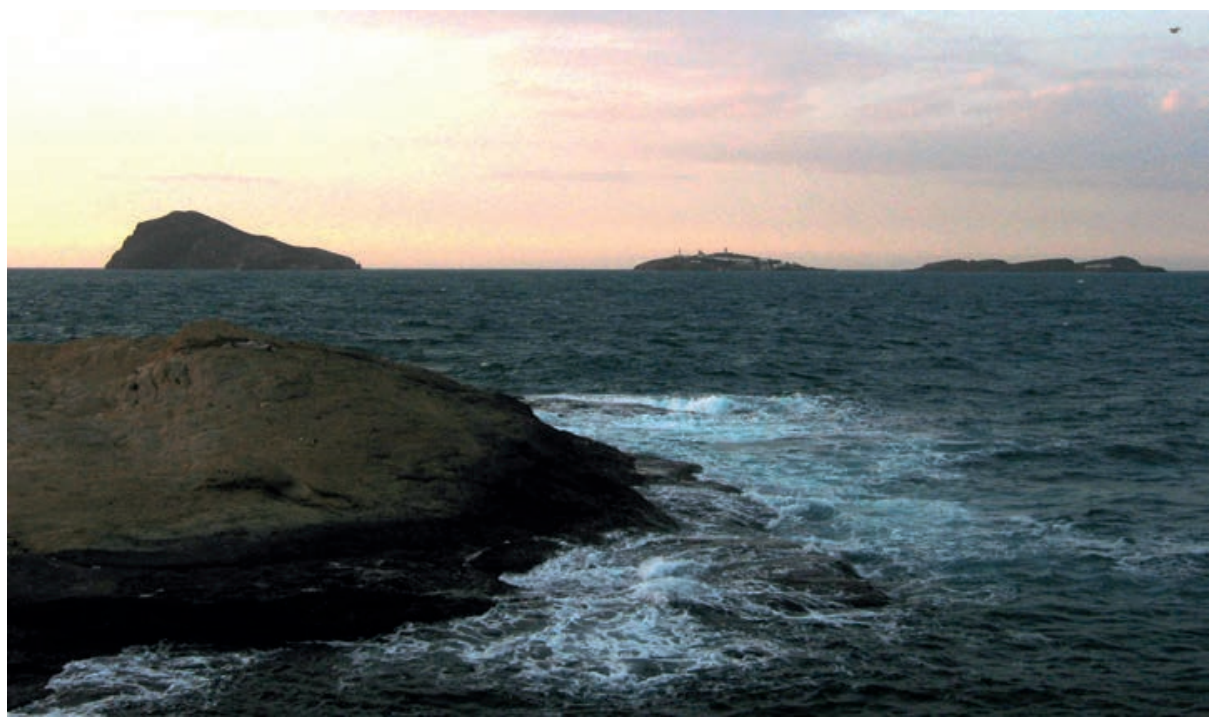

Cabo del Agua y las islas Chafarinas

En relación con este itinerario, no podemos obviar un expediente depositado en los archivos de la Real Academia de la Historia (CAML / 9 / 7962) en relación a dicha vía y su búsqueda que tendrán por raíz un estudio de Antonio Blázquez en 1902 (Blázquez, 1902) y la inclusión de par te de este trabajo en investigaciones posteriores. Los trabajos de búsqueda de diha vía se activarán en 
1916 por Fidel Fita, Director de la Real Academia de la Historia tras publicar su trabajo Melilla púnica y romanaa raíz de los hallazgos de San Lornzo, que escribía a Francisco Rafael de Uhagón, Marqués de Laurencin lo siguiente:

Mi distinguido amigo y compañero: mucho celebrare que el ilustre General Jordana en razón de la vía romana existe el cabo "Tres Forcas", que va por Melilla hasta Chafarinas, descrita en el último número del Boletín, interesa al Cuerpo de Ingenieros militares para que se haga el trazado de la misma vía con sus mediciones y se vea de recoger, si fuera posible, algunos de los miliarios que alli existieron ${ }^{4}$.

El general Jordana, Comandante General de Melilla hasta esos momentos señalaba al respecto en una carta al Marqués de Laurencin su interés por la vía romana.

Tenía encargado al General Aizpuru, pues estos descubrimientos han sido posteriores a mi salida de Melilla, que se cuidar a de observar y recoger cuanto pudiera relacionarse con tales estudios; y hoy le transmito el contenido de las citadas car tas, para que además de lo que y le tengo prevenido, de instrucciones a la Comandancia de Ingenieros relativas al estudio de la vía romana de Tres Forcas a Chafarinas. ${ }^{5}$

Finalmente La Real Academia de la Historia agradecerá la colaboración al general Jordana en otra carta.

...en el territorio de Melilla existen vestigios de la dominación romana, y que, al hacer obras o practicar excavaciones, se suelen hallar objetos de gran valor histórico, que hacen concebir la esperanza de mayores descubrimientos arqueológicos; por lo cuall.E. tiene encargado al Sr. General Aizpuru, cuide de observar y hacer recoger cuanto aparezca con relación a estos estudios así como transmitir las ordenes a la Comandancia de Ing enieros relativos al de la vía romana de Tres Forcas a Chafarinas, ofreciendo V.E. además comunicar todo aquello que juzgue de interés en relación con estos trabajos. ${ }^{6}$

${ }^{4}$ CAML / 9 / 7962/2 (1) Carta de Fidel Fita al Marqués de Laurencin (06-05-1916).

${ }^{5}$ CAML / 9 / 7962/2 (2) Carta de Gómez Jordana al Marqués de Laurencin (16 05-1916).

${ }^{6}$ CAML / 9 / 7962/2 (3) Car ta de la Real Academia de la Historia al General Gómez Jordana (Alto Comisario de España en Marruecos) agradeciéndole su colaboración. (15-06-1916). 
Uno de los periodos más oscuros debido a la escasa infor mación sería la época bajoimperial, donde una de las pr incipales fuentes como es la Tabula Peutingeriana tiene la parte o fragmento correspondiente a esta orilla destruido, aunque dicho segmento fue reconstruido por Konrad Miller. Datada a partir del siglo IV d.C. recogerá de forma gráfica las diferentes mansio del imperio romano. En la región de Quebdana relativas a esta fecha han sido localizadas monedas de Adriano y Marco Aurelio así como enAin Reggada una tabla paleocristiana datada en el siglo V d.C.

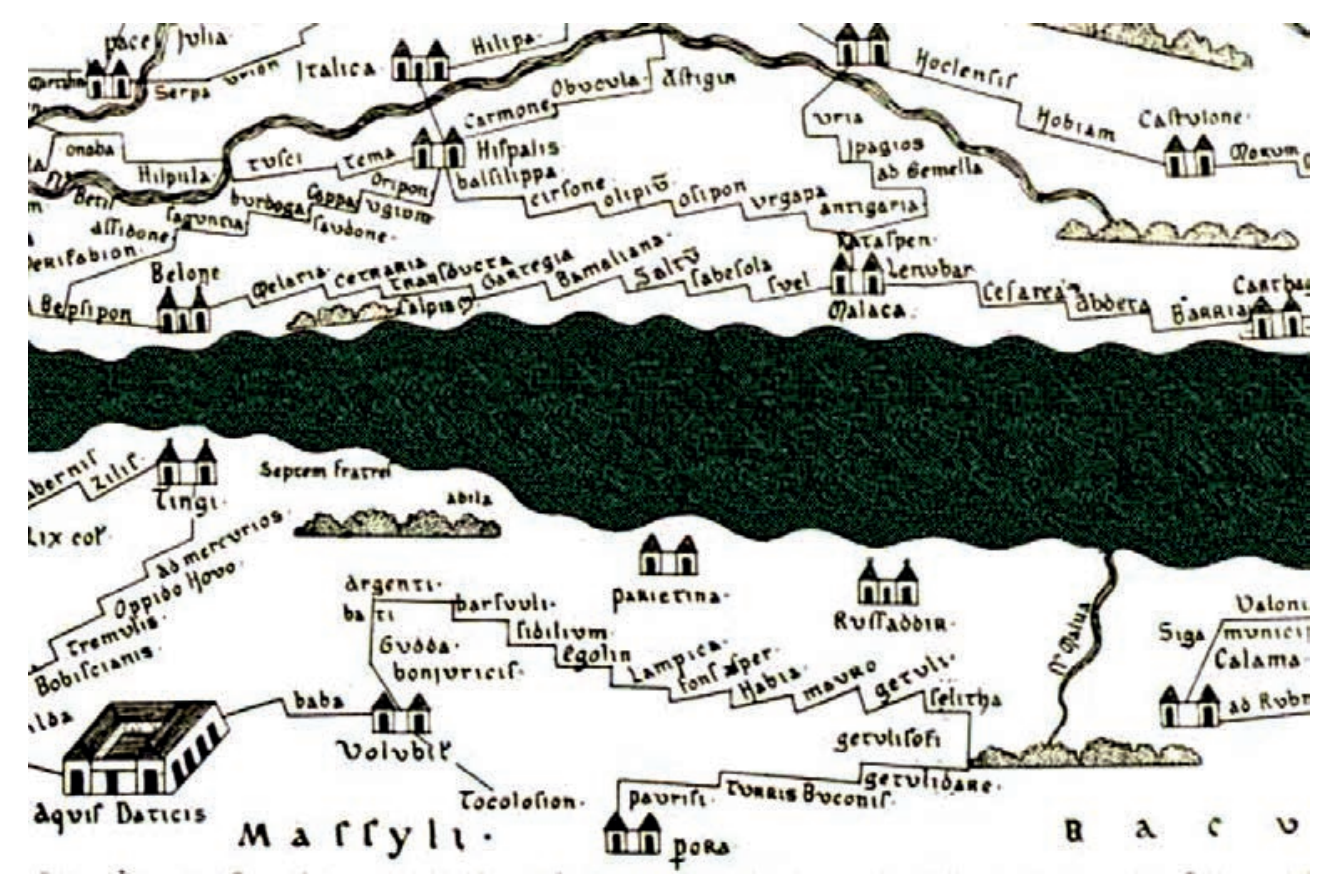

Primer fragmento de la Tabula Peutingeriana reconstruida por Muller (1887).

\section{DEL FIN DE LA ANTIGÜEDAD A LA ÉPOCA MODERNA}

A pesar de no identificar hasta la feha materiales de adscripción medieval, sin duda las islas Chafarinas debieron acoger, como en siglos anteriores, pequeños embarcaderos para las flotas pesqueras. Podemos señalar en un marco general algunas referencias que si no justifican la $g$ ran laguna existente, al menos otorgan la esperanza de identificar materiales en el futuro. 
A comienzos del siglo VIII los ejércitos m usulmanes propagarán su religión por el norte de África a las tribus bereberes, y no siempre con facilidad. El jefe yemení Salih B. Mansur se proclamará única autoridad en la zona deTensaman, siendo reconocido por el califa omeya de Damasco a comienzos del siglo VIII, fundando el emirato independiente con capital en la rcién fundada Nakur. En el área oriental, Yarawa será una de las ciudades más impor tantes en el margen derecho del Muluya.

El territorio de Quebdana durante el siglo X correspondía a Musa b. Abi 1-Afiya zona inhóspita entre dos ciudades por tuarias importantes como era Malila y Yorawa. Al- Muqtabis de Ibn Hayyan es una de las principales referencias que recoge los avatares de esta región. En el siglo X sería fundada Oujda por Ziri Ben Attia.

El Bekri en su Descripción del África septentrional, datada a finales del siglo XI d.C., señalaba que el viajer o que abandonaba el puer to de Melîla, dirección hacia el este, encontraba primero el puer to de la ciudad de Djeraoda, el cual tenía un b uen fondeadero, al lado del cual estaba un río que desembocaba en el mar. Desde ahí a las islas de Molouia [Djâferin] (Islas Chafarinas) indica que ha y ocho millas por el camino de tier ra. Frente a frente, sobre la costa de Andalucía y a la distancia de dos días de naegación, se encuentra Camdjala.

A mediados del siglo XII el geógrafo ceutí Idrisi en su Descripción de África y España mencionará una isla en la desembocadura de un río posibemente la isla de Congreso. Señalaba que de Kerat (Kilates) a Medina Melila por mar hay doce millas, y por tierra unas veinte millas; y de Melilla a la caída de la embocadura de río que viene de Arcasif habrá veinte millas; y delante de la desembocadura de este río hay una isla pequeña; y delante de este sitio de berbería medina Geraüa; y de la caída deWadi-Arcasif al puerto Tafir Kenit, que está sobre el mar y sobre el Hisn Munia Saguir cuarenta millas.

Las guías prácticas de los marineros denominados portulanos comenzaron a surgir a partir del siglo XIII d.C., en ellos se presentaban distintas referencias de la costa como cabos, ríos e islotes presentando rumbos y distancias entre los puertos de la ciudades y aunque carecían de coordenadas, sí presentaban una red de rumbos a partir de una rosa de los vientos central. 


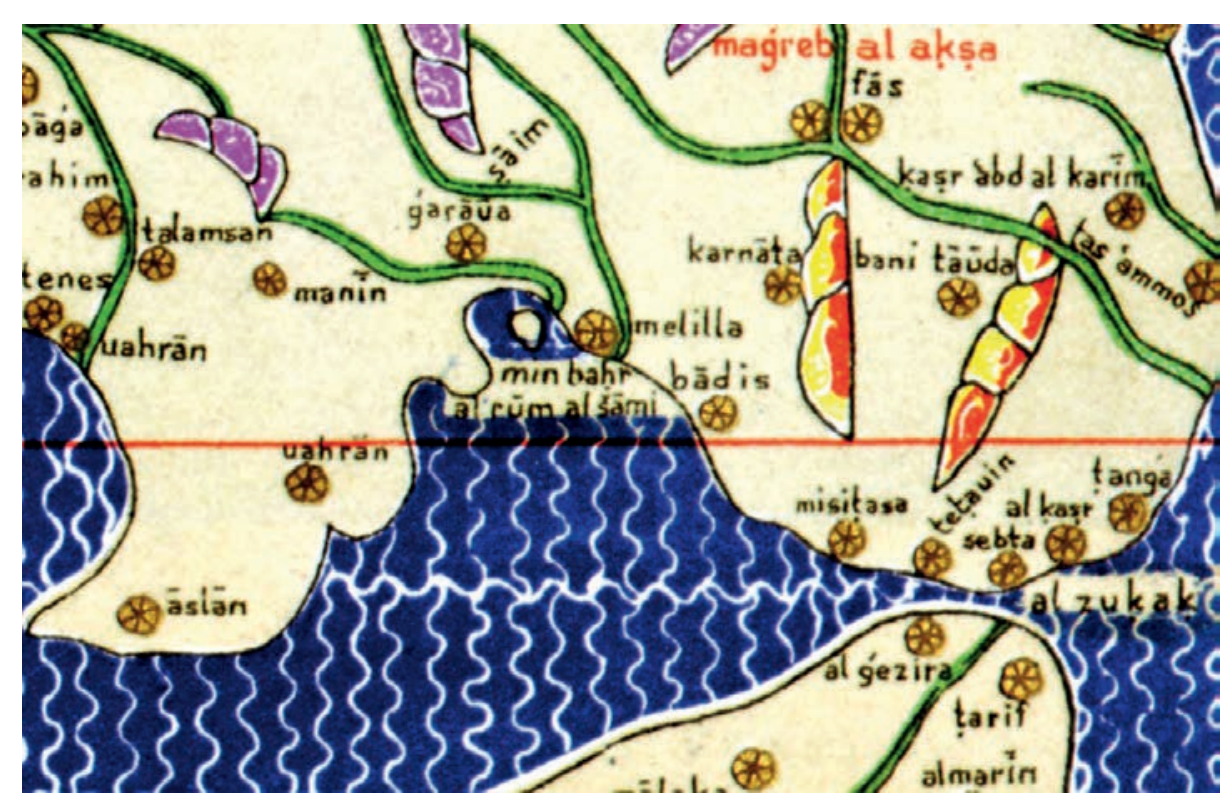

Fragmento del Mapa de Idrisi (1154) reconstruido por Muller, Charta Rogeriana.

Una de las pr imeras cartas portulanas conservadas que refleja toda esta experiencia náutica es la denominada Pisana, realizada aproximadamente en el año 1290. En este por tulano se representan tres islas, siendo una de ellas de mayor tamaño en alusión a la isla del Cong reso, donde aparece el tér mino de Jafarin en color rojo debido a su importante carácter portuario, poco alejada de esta primera referencia del medievo que nos legaba el onubense El Bekri.

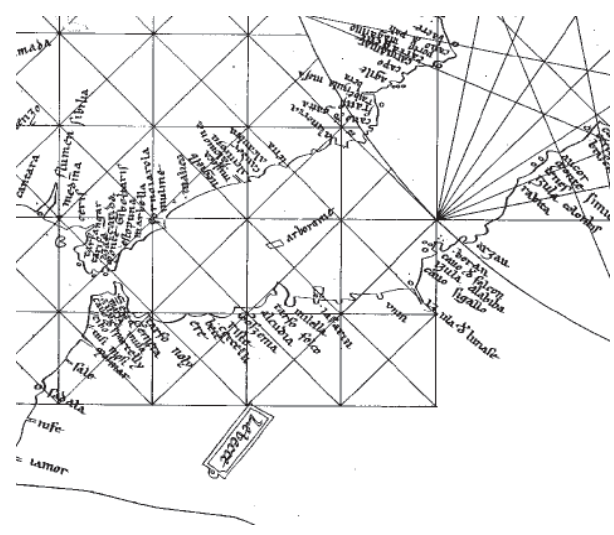

Fragmento de la Carta Pisana (1275).

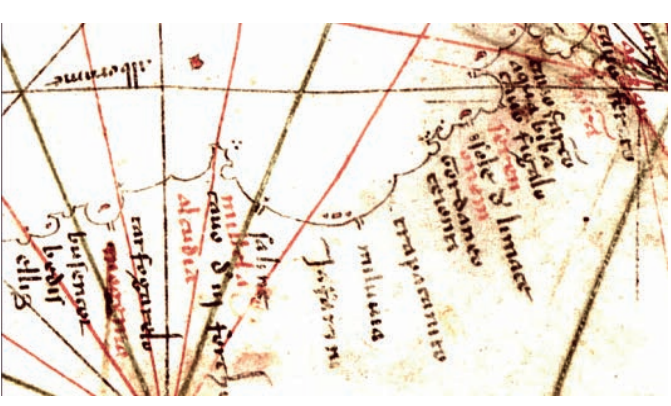

Fragmento portulano de Pedro Vesconte (1313). 
A pesar de los distintos autores, el viejo nombre de las Chafarinas no sufrirá grandes mutaciones. La diferenciación de i y j no se hará efectiv a hasta los siglos XV y XVI, igualmente la f de dobe trazado será habitual encontrarla en los siglos XIV y XV transcribiéndose ocasionalmente como Jaffarin. La confusión en el trazado entre i-j y la z llevó en el siglo XVI a transcribir el nombre por el de Zafarinos, al igual que la población en tierra denominada por el mismo nombre.

Así podemos verlas recogidas en la mayoría de los portulanos medievales de los que destacaremos tan solo algunos. En el atlas náutico de Pedro Vesconte aparece como Jafarin (1313), Jaffarim en el Liber Fidelium del taller deVesconte (1321), el cartógrafo mallorquín Angelino Ducert recogerá Jafarin (1339) así como Doménico y Francesco Pizzigani (1367),Zafarins en el AtlasTammar-Luxoro, en el Atlas Catalán aparece Jaffarini (1375), Zafarini en elAtlas de Pinelli (1384), Dalasanil en la anónima Carta Magrebí (1400), Zafarin en Carte marine d'une partie de l'océan Atlantique Nord-Est, de la mer Méditerranée et de la mer Noire de Virga (1409), Zafarini en el Atlas de Andrea Bianco (1436), Jafarin en Uzzano (1442), Isole di Jafarini en el derrotero de Magliobechi XII, Jaffarime en Magliobecchi XIII, Caffarinj en la carta de Giroldi (1450), Jafains en la carta del museo Meereskunde (1453), en el portulano de Pareto señalará Jaffarim (1455). En el atlas de Gratiosus Beninchasa aparecerá como Jafariny (1466 y 1467), Jafanis en la carta de Cristóbal Colon de finales del XV y por último señalar el minucioso Fessa Tractus del v eneciano Livio Sanuto donde figuran como Infferino (1558).

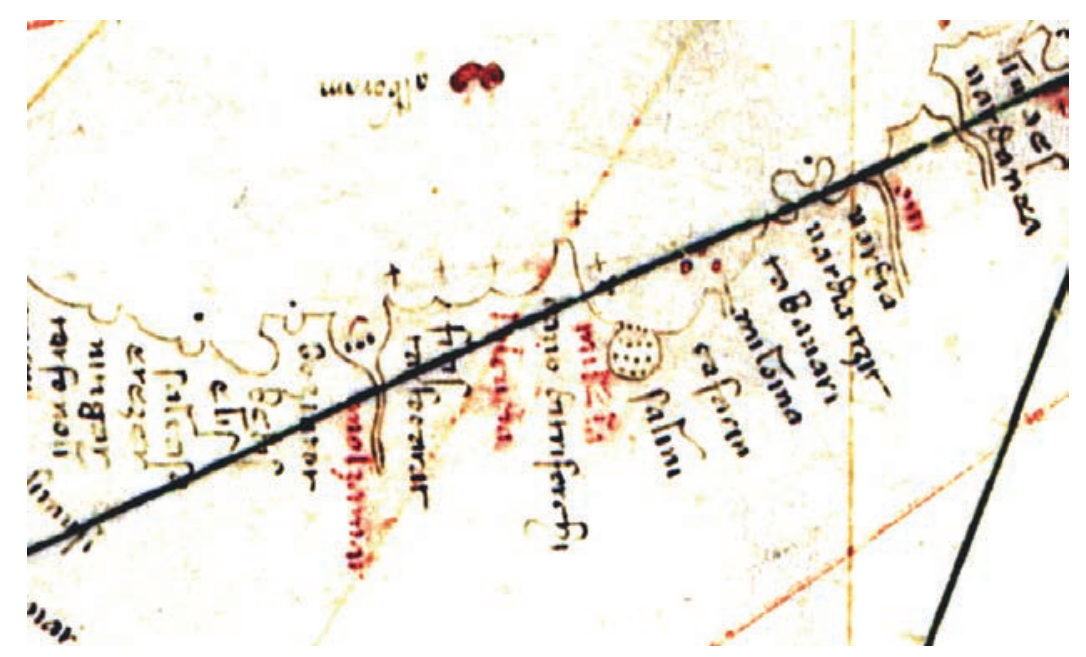

Fragmento del portulano de Albertino de Virga (1409). 


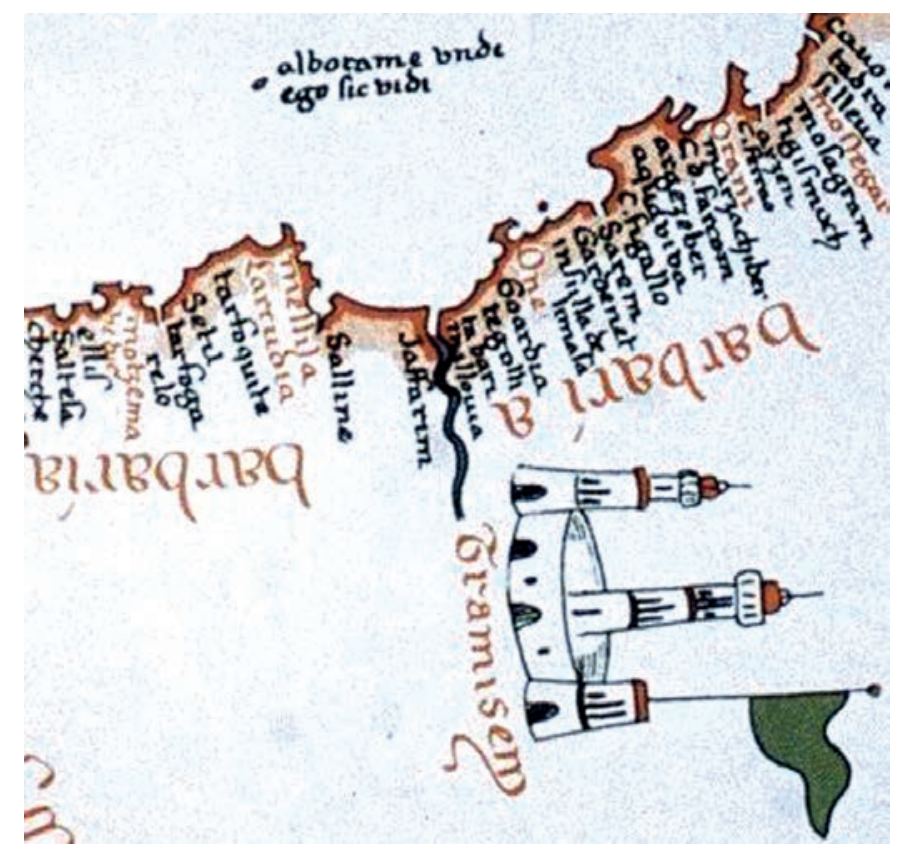

Fragmento del portulano de Bartolomé Pareto (1455).

Como punto final a estas notas en torno al archipiélago de las islas Chafarinas podemos señalar cómo a finales del medievo e inicios del periodo moderno, diferentes escritores recogieron ese desolado paisaje que constituía la Quebdana frente a las islas Chafarinas destacando Al Badisi, León el Africano y Mármol Carvajal.

Abd al-Haqq ibn Ismail al-Badisi, natural de la antigua Badis cercana a la actual Alhucemas a comienzos del siglo XIV elaboró un compendio de santos del Rif. Como nos transmite, la zona de Quebdana era una egión desértica terrible, con abundantes animales salvajes, al margen de las zonas pobadas y con bastante frecuencia aparecían asaltantes, ladrones y cristianos que llegando del mar realizaban emboscadas. A su juicio solamente un grupo numeroso de personas podía cruzar dicha zona, la cual tenía cuarenta millas, comenzando en Melilla y continuando hasta comienzo de los barrancos (lJanâdiq) de Kabdân.

Conocidos como montes Echebdeuon durante la primera mitad del siglo XVI, León el Africano en su Descrittione dell'África señalaba que se extendía de Chasasa hasta el rio Muluia hacia el levante y del Mediterráneo hasta el desierto de Garet por el sur. Muy poblada en tiempos por hombres ricos y valientes, produce miel en ab undancia y cebada, y 
tiene ganado abundante porque su suelo es bueno y el Alfoz entero tierra dentro es una extensa dehesa. Pero al tomar los españoles Chasasa, estos montañeses no pudieron mantenerse en la comarca por la gran lejanía entre los pueblos y por sus divisiones. Los abandonaron y quemaron las casas para ir a vivir a otras montañas con sus propiedades.

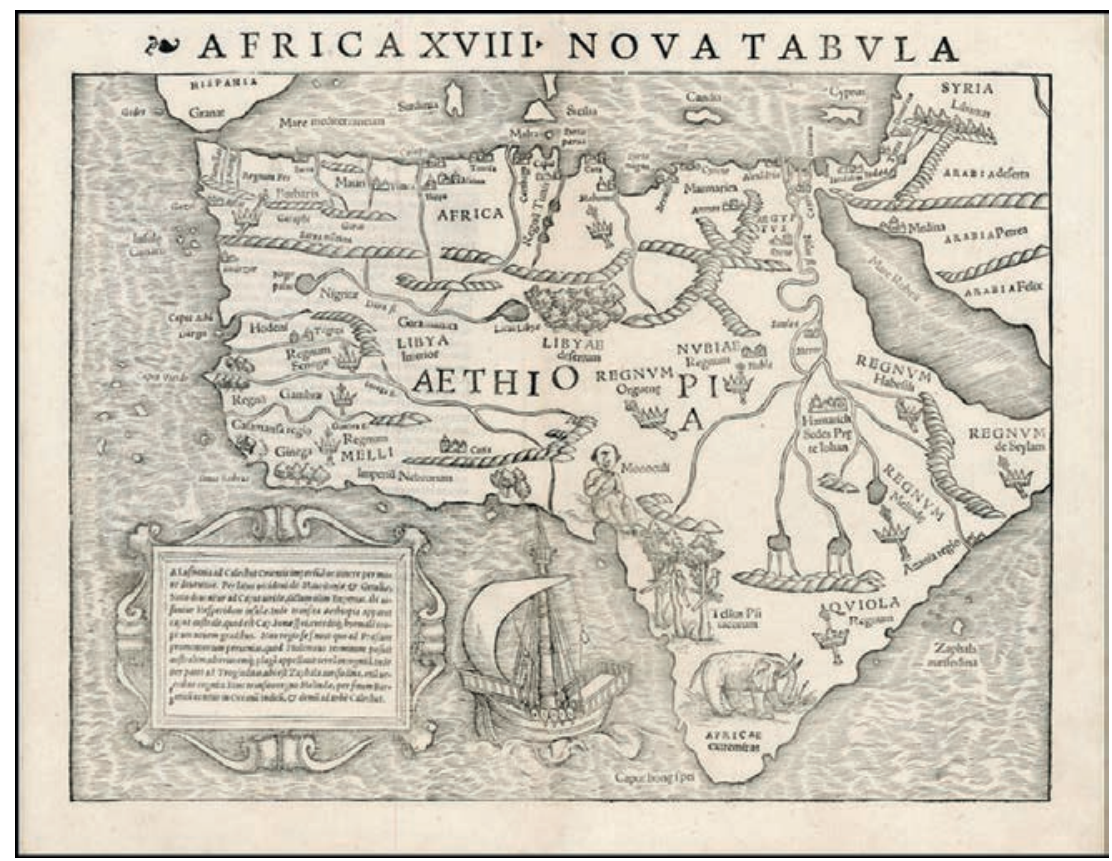

Tabula de Sebastian Münster realizada hacia 1540.

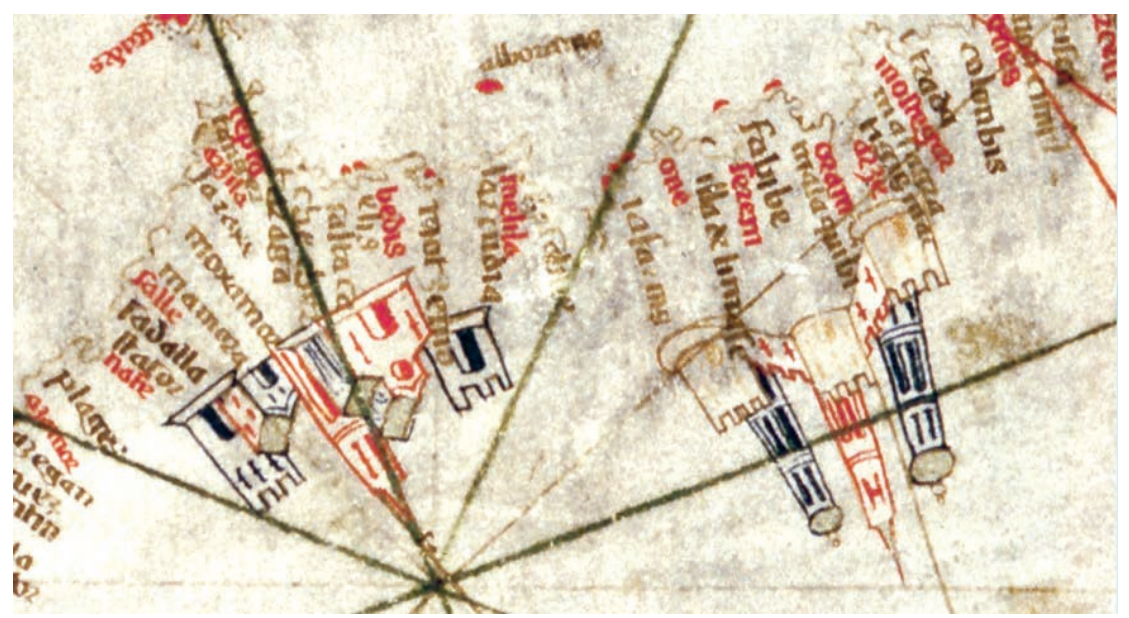

Fragmento de la carta marina de Colón $\left(2^{a}\right.$ mitad XV). 


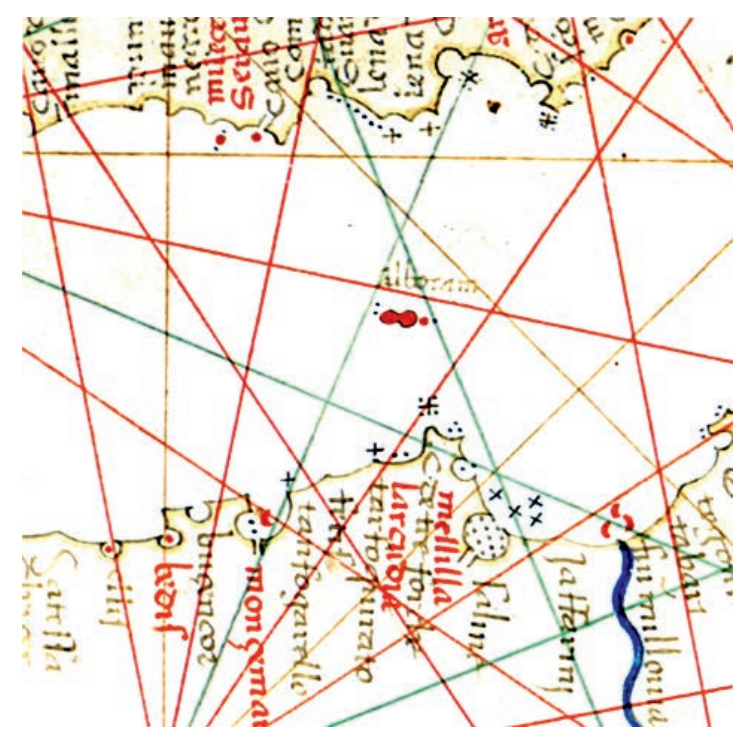

Fragmento del atlas náutico Grazioso Benincasa (1467).

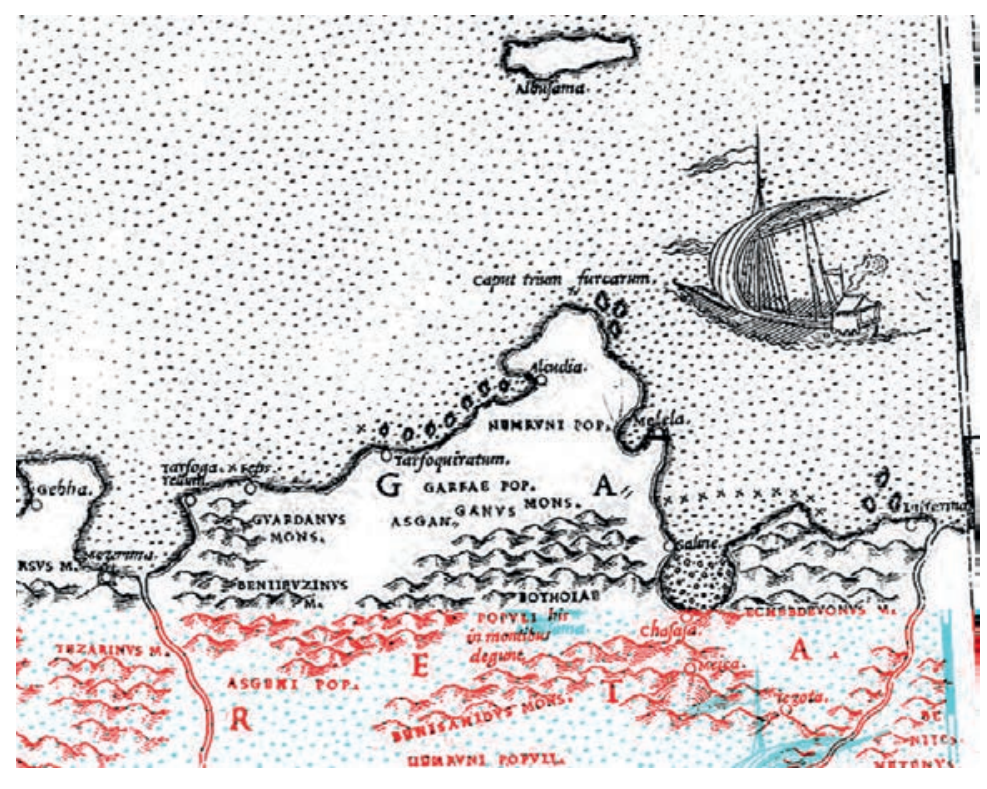

La costa del Rif en el siglo XVI (Livio Sanuto).

La obra tendrá gran influencia sobre Descripción general de África del granadino Mármol y Carvajal señalando sobre la región que la sierra de Mequeb Huan es muy grande, cuyo promontorio o cabo que cae sobre el rio Mulucan, llaman los cristianos sierra e las adargas y por la otra parte que cae sobre la mar la llaman sierra de el Carmun 
donde fue la antigua ciudad de Mezuxa, cuyos edificios parecen haber sido hechos por los romanos, después fue destruida por aquel halifa cismático de Caruan que habemos nombudo muchas veces y aunque no se volvió a poblar enteramente viven en lo más alto de ella unos bereberes africanos en un barrio que hoy llaman Mezuxa la nueva.

Esta tierra es muy grande y se extiende desde la ciudad de Cazaza par a levante hasta el rio MuluyaY desde el Mediterráneo Ibérico hasta los desiertos de Garet. La qual dicen los escritores que estuvo antiguamente poblada por un pueblo rico y belicoso y que había mucha contartacion. Es abundante esta tier ra de cebada y de miel y de g anados mayores y menores y cuando los cr istianos ocuparon Melilla eran tantas la Cor reias que hacian capturando los moradores de ella y llevandoles los ganados cada dia sin ser pate de defenderse porque los lugares estaban arredrados uno de otros, que quiero por desemprara sus casa y haciendas y se ueron a vivir aotr as tierras mas adentros. Mas después que se perdio Cazaza han vuelto a ellas aunque no con tanta prosperidad como primero. Llaman de estos bereberes beni Sahid Y son vasallos del Alcayde de Tezota y coge de ellos tr ibutos para sustentar la caballería que tiene en guardia la provincia.

La historia de las islas Chafar inas, como se ha visto en estas líneas, es muy extensa y por tanto requiere del adecuado diseño de estrategias de investigación, protección y difusión, al igual que se ha hec ho con su patrimonio natural, con el imprescindible apoyo financiero de la administración así como la participación de otras instituciones. Solo de este modo se podrá valorizar de forma global el vasto patrimonio cultural de estas islas transmitiéndose a las futuras generaciones.

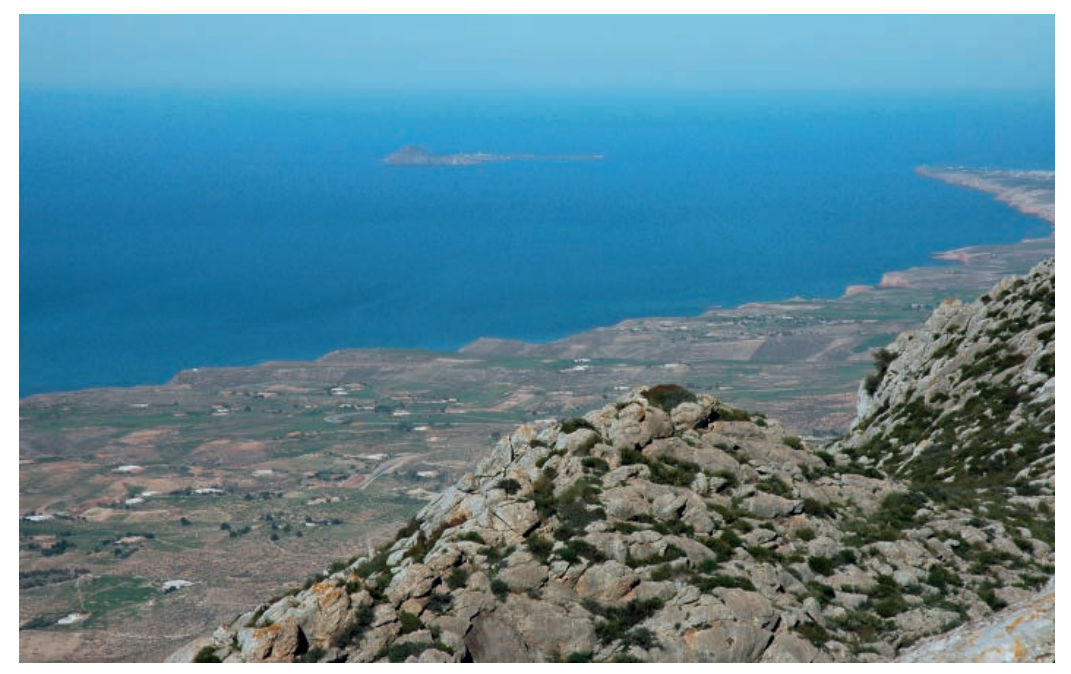

Costa africana y las islas Chafarinas frente al Cabo del Agua, vista desde la Quebdana. Foto: Novomig. 


\section{BIBLIOGRAFÍA}

ARAGÓN, M. (2008): "La protección de patrimonio arqueológico de Melilla. La carta arqueológica terrestre (1881-2007)”, Akros. La revista del Museo, 7 , pp. 87-94.

BRAVO, A. y FERNÁNDEZ, P. (Directores) (2005): Historia de Melilla. Melilla, Ciudad Autónoma de Melilla, Consejería de Cultura y Festejos, 886 pp. BLÁZQUEZ, A. (1902): "Vía romana de Tánger a Cartago", Boletín de la Sociedad Geográfica, 43, pp 324-351.

BLÁZQUEZ, A. (1909): "Vía romana de Tánger al río Muluya según el Itinerario de Antonino (Siglo III d.C.)”, Boletín de la Real Academia de la Historia, LV, pp 366-367.

EL AFRICANO, J. L. (2004). Descripción General de África y de las cosas peregrinas que hay allí. Fundación el Legado Andalusí.

CRESSIER, P. (2000): "La fortificación urbana islámica en el Nor te de Magrib al-Aqsa: El caso de Melilla”, ElVigía de Tierra, 6, pp. 23-45.

DOMÍNGUEZ, S. (1984): “Breve historia de las Islas Chafarinas”, Aldaba, 3, pp. 41-49.

FERNÁNDEZ, R. (1945): Melilla prehispánica: apuntes para una historia del septentrión africano en las Edades Antigua y Media. Madrid, Instituto de Estudios Políticos, 537 pp.

GOZALBES, G. (1989): Estudios sobre Marruecos en la Edad Media. Granada, 369 pp. GOZALBEZ, E. (1984): "Relaciones comerciales entre Carthago Nova y Mauritania durante el principado de Augusto", Anales de la Universidad de Murcia, 1982-83, XL 3-4, pp. 13-36.

GOZALBES, E. (1991): La ciudad antigua de Rusadir apor taciones a la histor ia de Melilla en la antigüedad, Melilla, Fundación Municipal Sociocultural.

GOZALBES, E. (1999): “Introducción al estudio de la Melilla Medieal”, ElVigía de Tierra, 4-5, pp. 89-104.

GOZALBES, C. (2008): “La Costa del Rif en la Cartografía Medieval». VII Estudios de Frontera. Alcalá la Real.

KBIRI, M. (2007): Revisando Kuass (Asilah, Marruecos) taller alfarero y enclave fenicio, púnico y mauritano, Saguntum-extra 7. Valencia, 249 pp.

MÁRMOL, L. (1573): Libro tercero y segvndo v olumen de la pr imera parte de la defcripcion general de Affrica con todos fucceffos de guerra, y cofas memorales. Dirigida a la C.R.M. del Rey Don Phelippe fegundo defte nombre. Granada. 
MIR, F. (1983): Melilla. Floresta de pequeñas histor ias. Melilla, Ayuntamiento de Melilla, $220 \mathrm{pp}$.

MIR, F. (1993): Con el viento de la Historia. Melilla, 369 pp.

RODRÍGUEZ, N. (1910): “La pesca en la costa iifeña. Las industrias pesqueras”, La Correspondencia de España, Miércoles 9 de febr ero de 1910, Año LXL, núm. 18.991, pp.1.

LÓPEZ, F. (1990): «Sobre la expansión fenicio-púnica en Mar ruecos. Algunas precisiones a la documentación arqueológica», Archivo Español de Arqueología, 63, pp. 7-41.

LÓPEZ, F. (1987): Mauritania Tingitana: de mercado colonial púnico a pro vincia periférica romana. Madrid, Universidad Complutense (ColecciónTesis Doctorales, no $83 / 87), 684$ pp.

SALVÁ M. y SAINZ P. (1921): La posesión de las Islas Chafarinas: informe. Editorial Reus, 7 pp.

SÁEZ, J. (1988): “Atlas arqueológico de Melilla”, Trápana. Revista de la Asociación de Estudios Melillenses, 2, pp. 20-28.

SARO, F. (1983): "Melilla cien años de hallazgos arqueológicos", Aldaba, Revista del Centro Asociado de la UNED de Melilla, 1, pp. 77-84.

TARRADELL, M. (1960): Marruecos Púnico. Tetuán, Cremades, 356 pp.

TAHIRI, A. (2002): "Proceso de urbanización en el Rif. Situación actual y perspectivas de investigación (Siglos VIII-X)”, II Congreso Internacional. La ciudad en al-Andalus y el Magreb. (Algeciras, 26-29 de noviembre de 1999). Algeciras, 1999, pp. 37-47.

TAHIRI, A. (2007): Rif Al-Magrib y Al-Andalus. Granada, Legado Andalusí, 230 pp. TISSOT, C. (1878): Recherches sur la géographie comparée de la MaurétanieTingitane. Paris.

VERNET, J. (1979): Estudios sobre la Histor ia de la Ciencia Mediev al, Barcelona, 508 pp. 